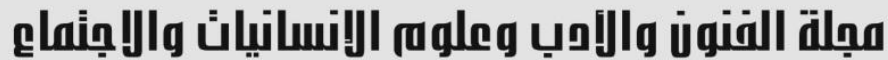

Journal of Arts, Literature, Humanities and Social Sciences

\section{قِدم العالم عند ابن رشد}

وزارة الأوقاف والثمد نبئون الاينية ـ اربيل ـ اقليم كردستان العراق malik9dilshad@gmail.com :الإيميل ونداف

كلنا نعلم أن العالم تطلق على مـاسوى اله تعالى في هذا الكون، وقضية قدم العـالم أو حدوثه تعتبر قضبة من القضايا التي اختلف فيها الفلاسفة والمفكرون و أصبحت مثار جدل وخلاف بين أهل الفكر، فمنهم من قال بقدم

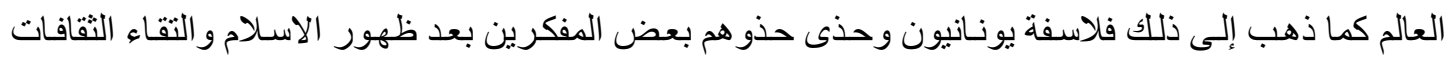
الأخرى بالثقافة والفكر الإسلامي. كما ذهب البعض الآخر إلى أن العالم حادث وليس بقديم، أحدثه الله وأوجده بعدما لم يكن. ومن الفلاسفة الإسلاميين من قال بقدم العالم وأنـه كان منذ قديم ولم يكن هنالك وقت محدد نقول بـأن العالم قد بعائ احدث فيه، كما قال بذلك ابن رشد. هذا البحث يحاول أن يسلط الضوء على هذه القضية وأن يذكر الأدلة التي اعتمد عليها كلا الفريقين من القائلين

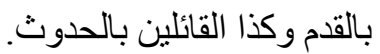
كما يحاول البحث ابر از رأي ابن رشد في هذه القضية، وكذا الأدلة التي ذكر ها ابن رشد واعتمد عليها على أنها

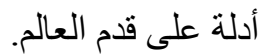




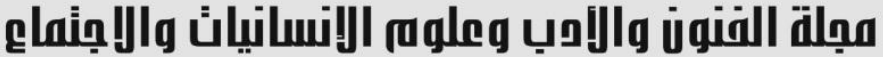

Journal of Arts, Literature, Humanities and Social Sciences

\section{The World Seniority at Ibn Rushd}

\section{Moslih Ahmed Nabee}

Ministry of Endowments and Religious Affairs - Erbil - Kurdistan Regiosal - Iraq Email: malik9dilshad@gmail.com

\begin{abstract}
We all know that the world calls what God Almighty is in this universe, and the issue of the world's seniority or its occurrence is considered one of the issues in which philosophers and thinkers disagreed and discussed a matter of controversy and disagreement among the people of thought of thinkers after the rise of Islam and other cultures meeting Islamic culture and thought.

Others have also argued that the world is an accident and not an old one, created by God and created it after it was not.

And among the Islamic philosophers, who said that the world was old and that it was from an old time and there was no specific time we say that the world has happened in it, as Ibn Rushd said.

This research tries to shed light on this issue and mention the evidence that both teams relied on by those who say the foot as well as those who say.

The research also tries to highlight Ibn Rushd's opinion on this issue, as well as the evidence that Ibn Rushd mentioned and relied on as evidence on the world's seniority.
\end{abstract}

Keywords: seniority of world, Ibn Rushd. 


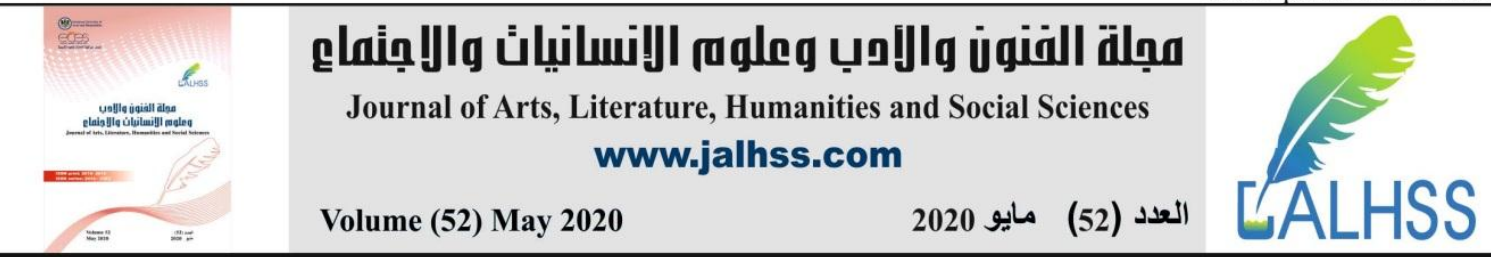

الحمد لله الذي خلق السمو ات والأرض وجعل الظلمات و النور ثم الذين كفروا بربهم يعدلون ، و الصـلاة و السلام على ولى

المقدمة

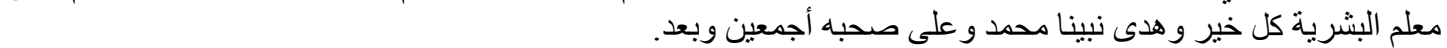

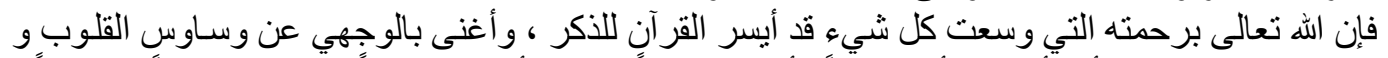

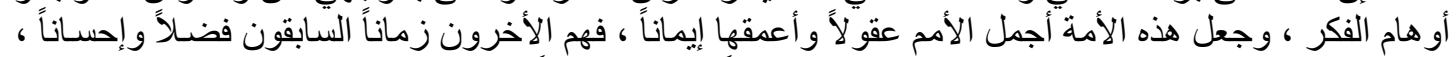

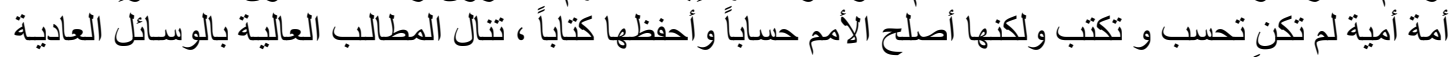

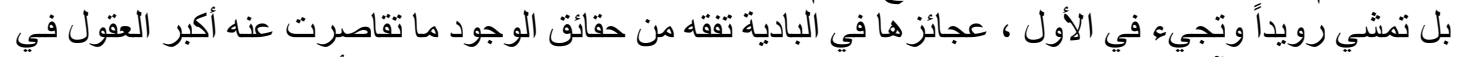

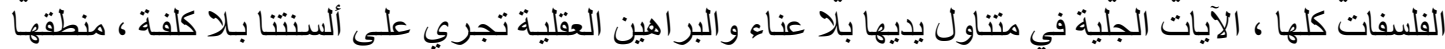

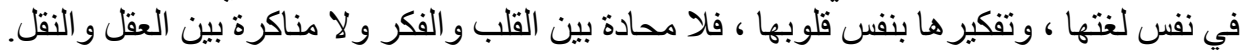

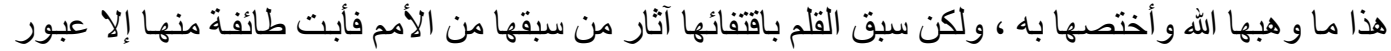

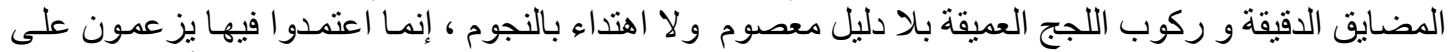

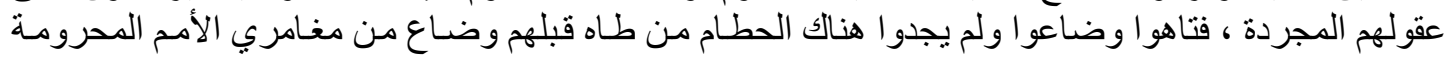

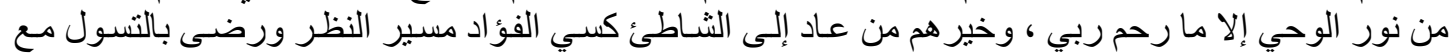

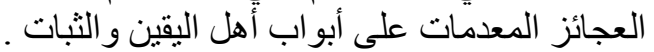

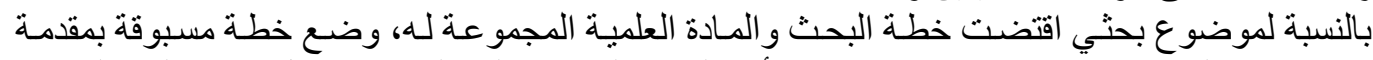

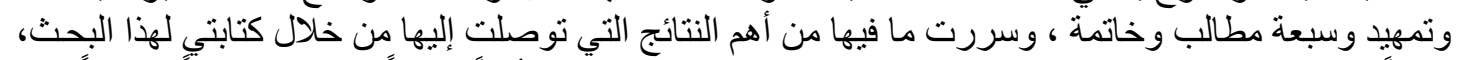

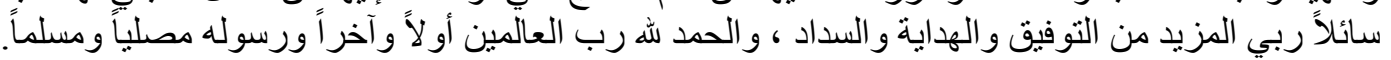

إن الفلسفة بصمة عامة ، وليست إلا التفكير العقلي المتعمق المتزن الذي يرشد الإنسان إلى الطريق الإلى الأقوم

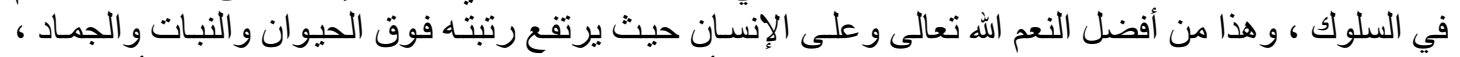

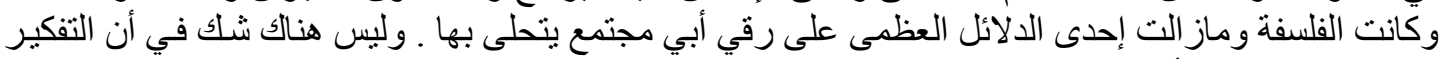

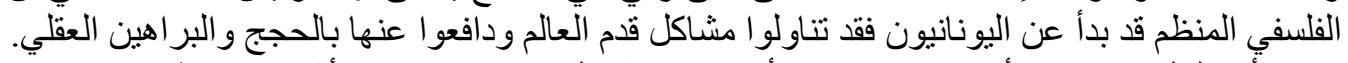

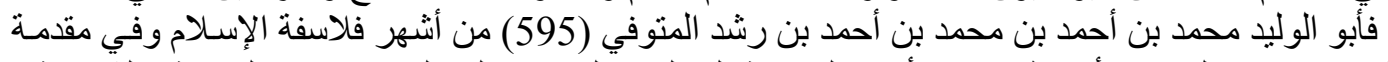

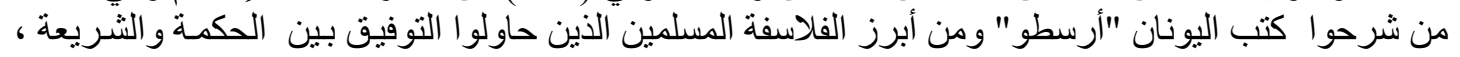
ونال بسبيها محنة كبيرة وكانت لله مصنفات كثيرة في الفلسفة وعلم الكئ الكلام نذكر ذللك في ترجمته إن شـاء الله 


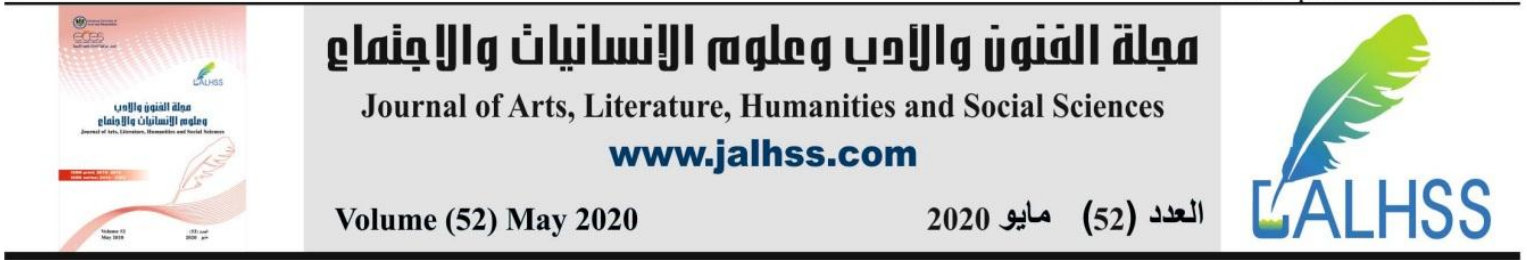

\section{المطلب الاول ترجمة موجزة لابن رشثد}

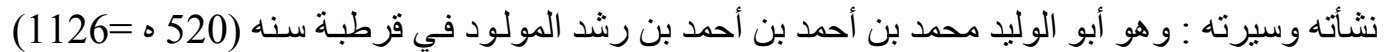

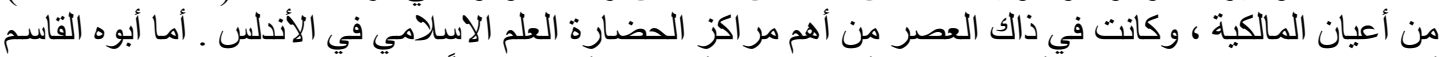

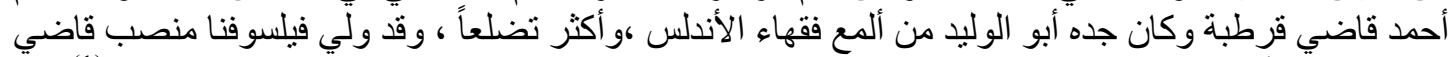

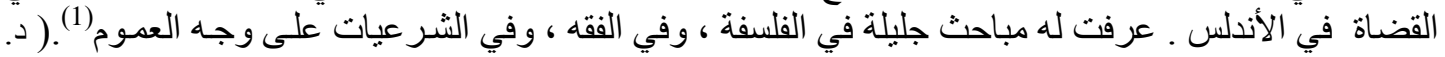

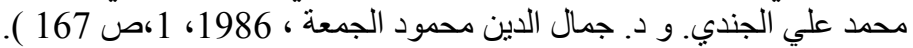

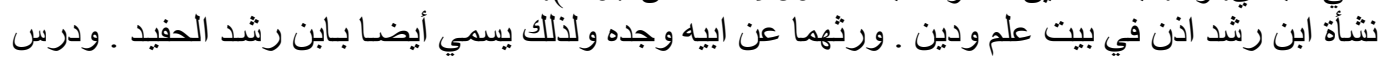

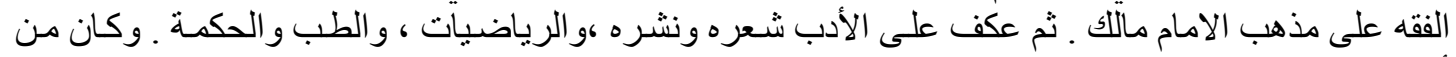

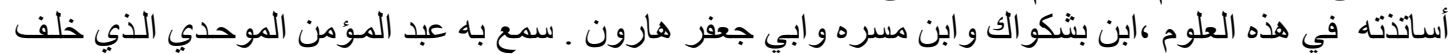

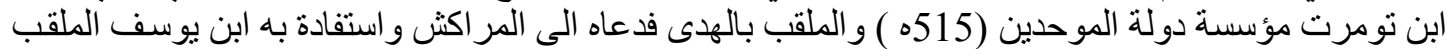

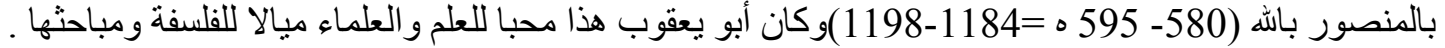

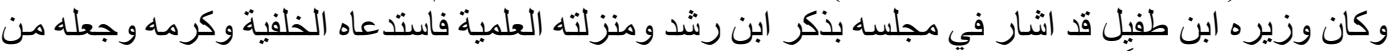

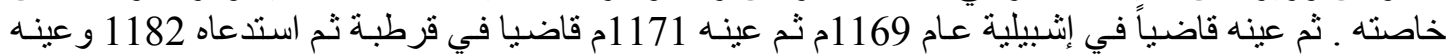

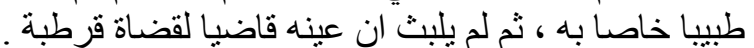

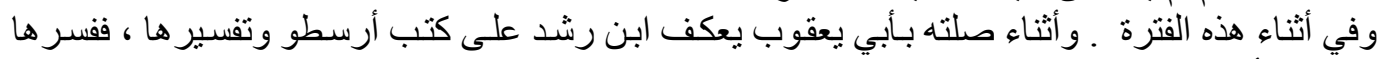

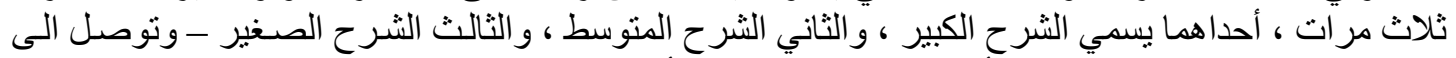

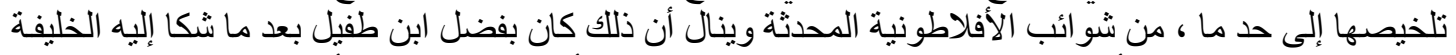

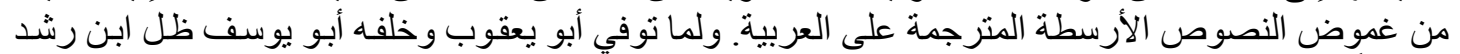

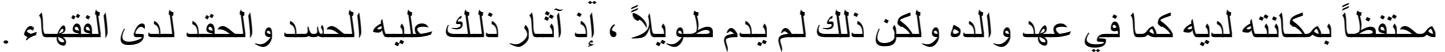

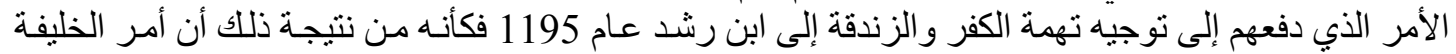

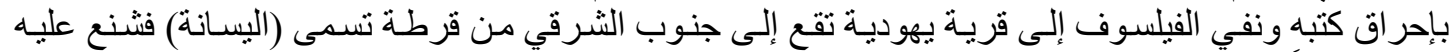

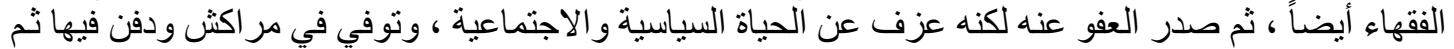

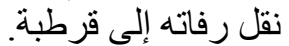

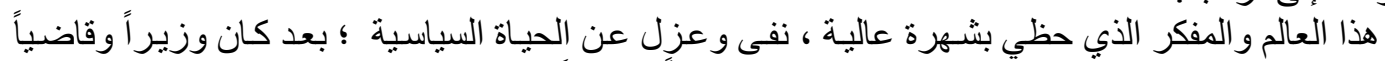

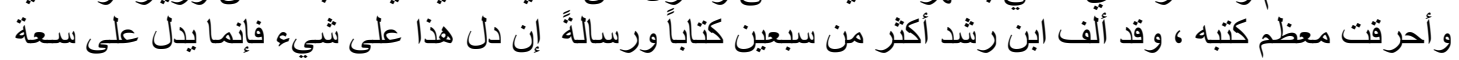

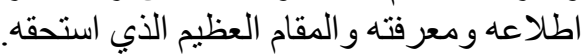

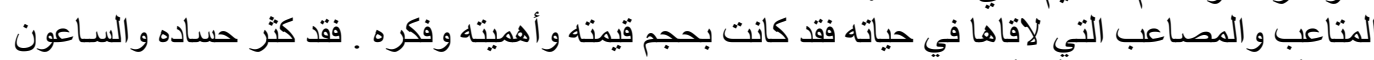

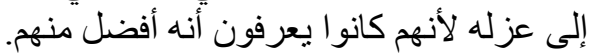

$$
\begin{aligned}
& \text { أهم كتبه: } \\
& \text { تهافت التهافت _ـرد على الإمام الغز الي. }
\end{aligned}
$$

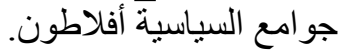

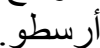

$$
\begin{aligned}
& \text { شرح أرجوزة ابن سينا.(2) (ابن رشد ، د س ، 2، ص ص } 9 \text { ). } \\
& \text { الكثف عن مناهج الأدلة في عقائد الملة. } \\
& \text { بداية المجتهد ونهاية المقتصند. }
\end{aligned}
$$

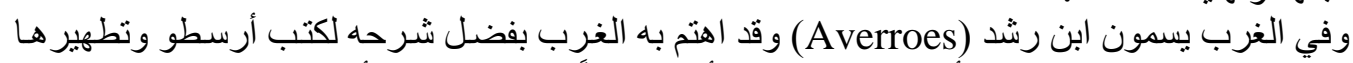

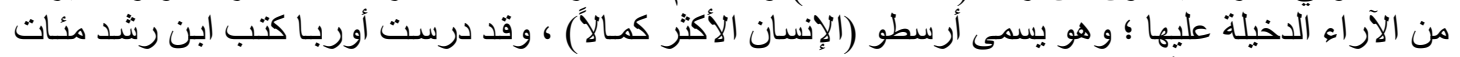

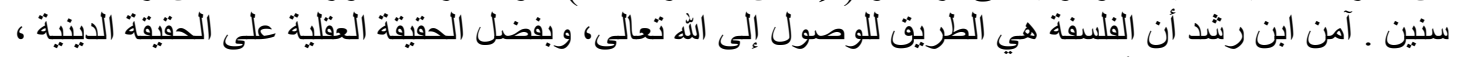

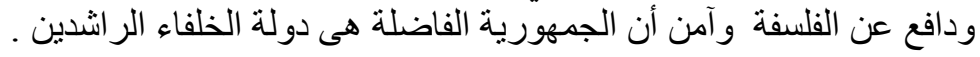




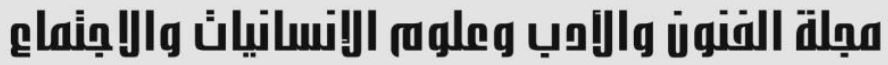

Journal of Arts, Literature, Humanities and Social Sciences www.jalhss.com

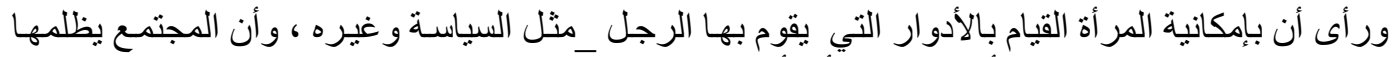

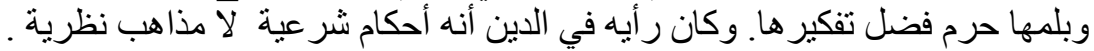

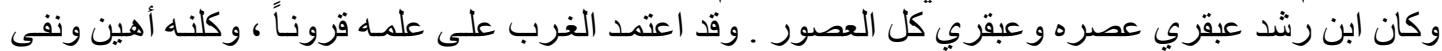

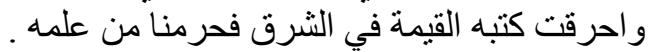

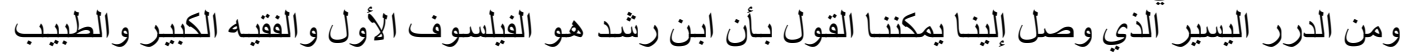

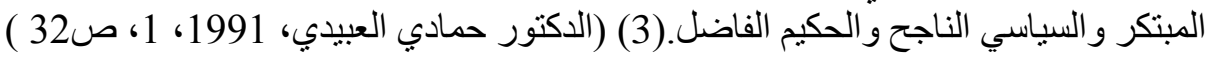

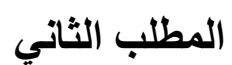 تعريف قدم العالم وحدوثنه}

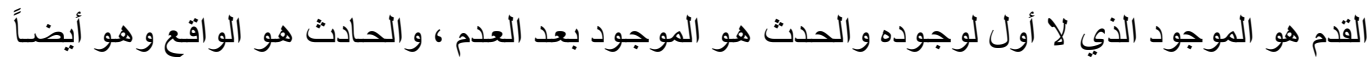

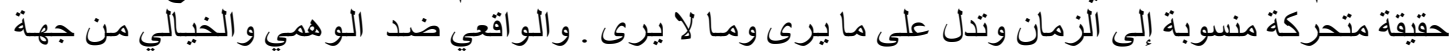

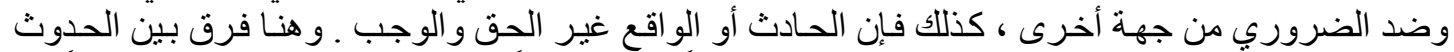

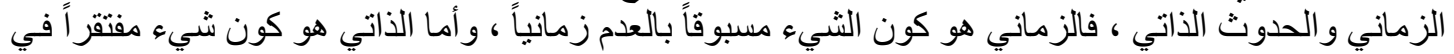

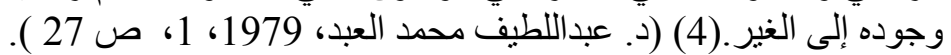
مفهوم العالم المعير

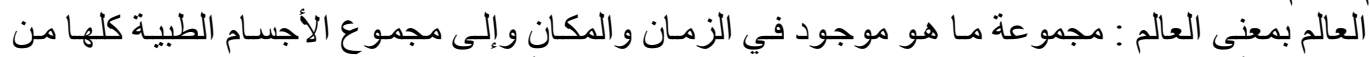

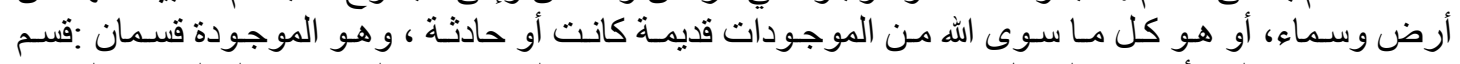

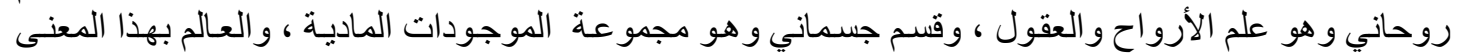

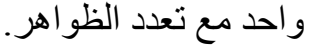

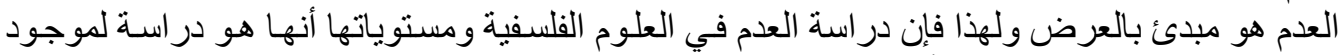

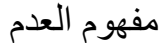

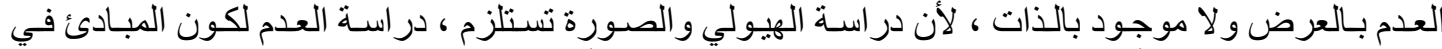

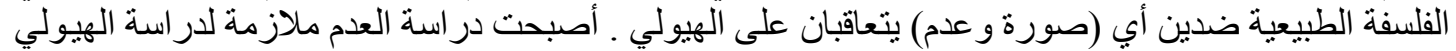

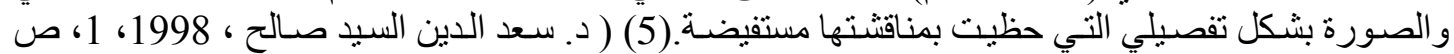

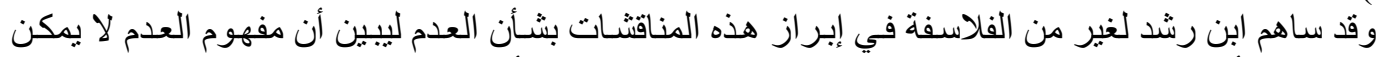

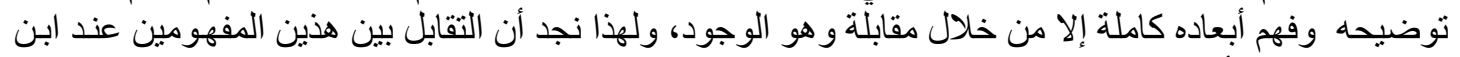

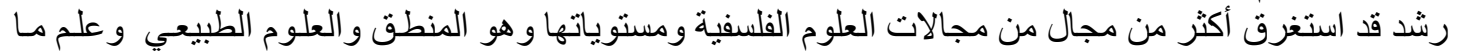

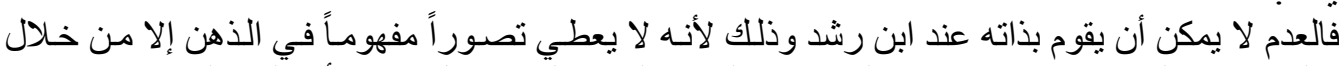

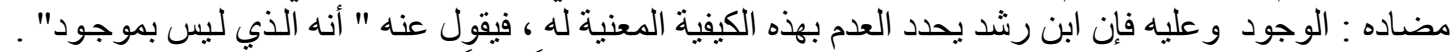

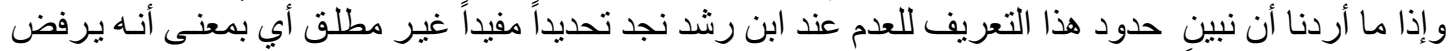

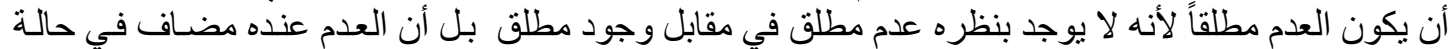

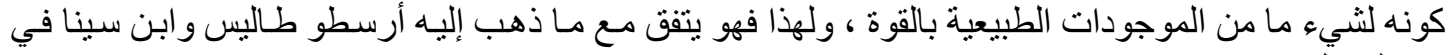

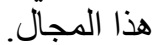

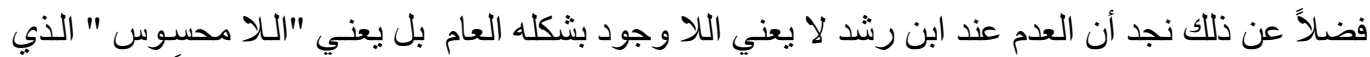

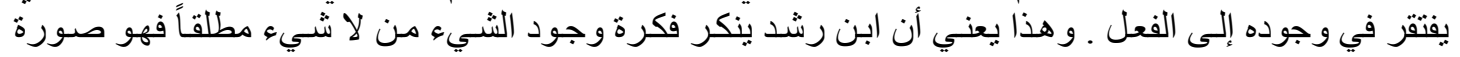

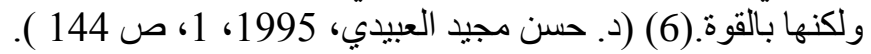




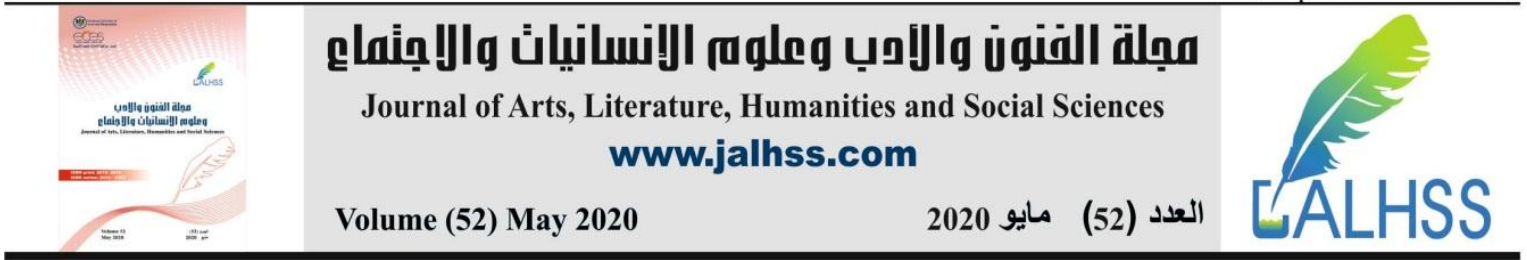

\section{المطاب الثالث \\ استعمال لفظ الحدوث و القدم}

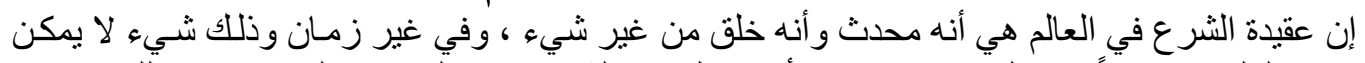

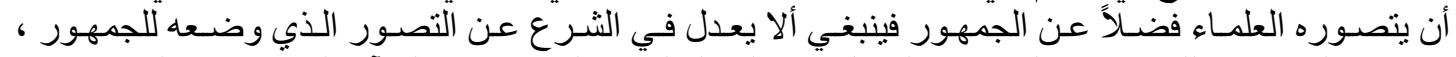
ويصر ح لهم بغير ذللك فإن هذا النوع من التمثيل في خلق العالم هو الموجود في القرآن الكريم وفي التور الته وفي التي

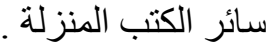

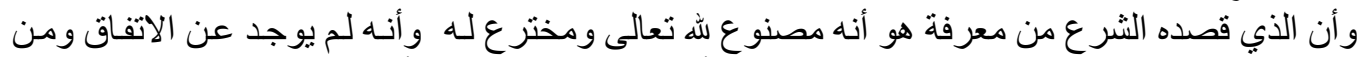

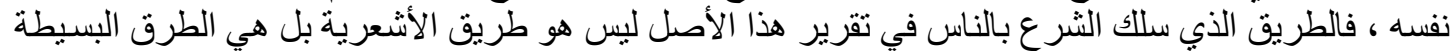

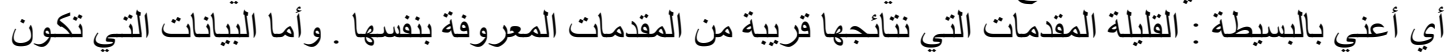

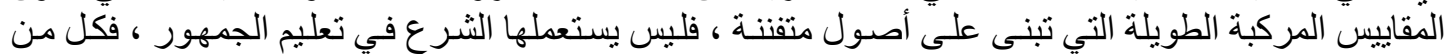

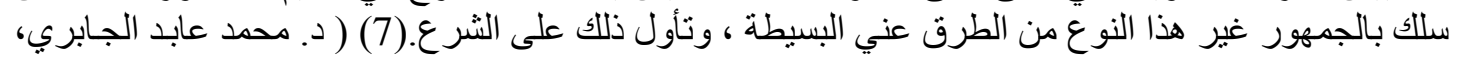

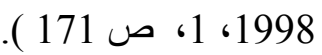

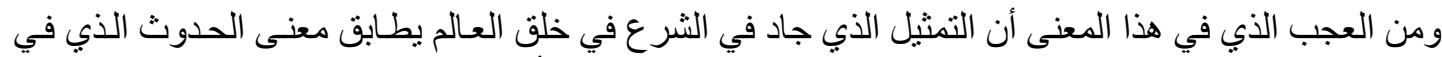

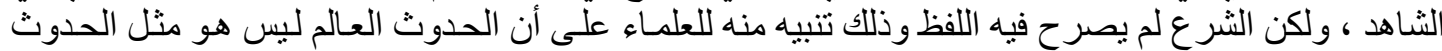

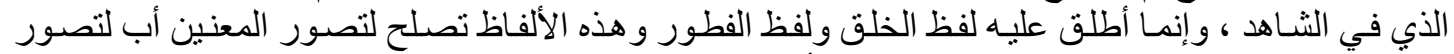

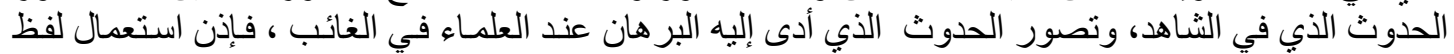

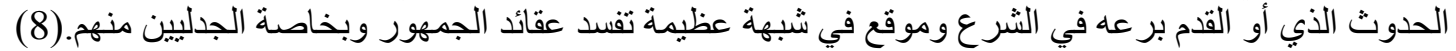

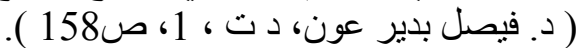

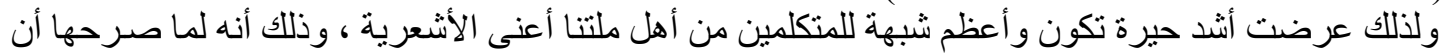

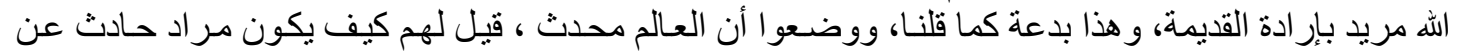

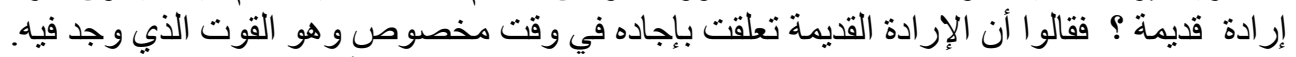

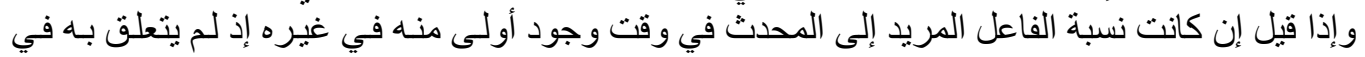

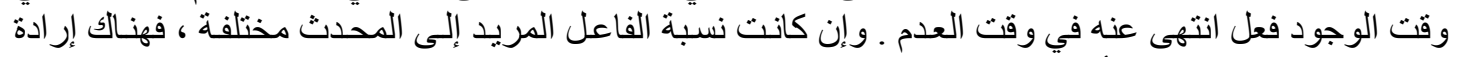

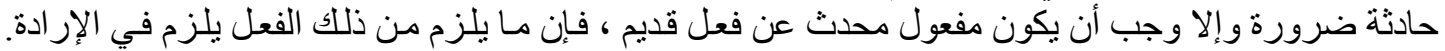

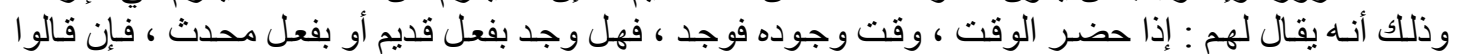

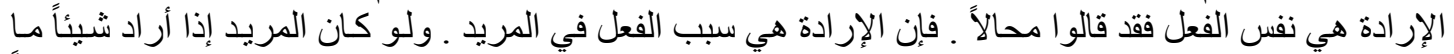

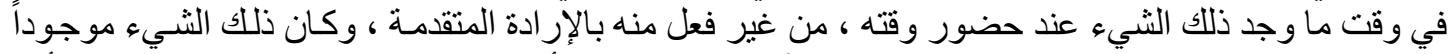

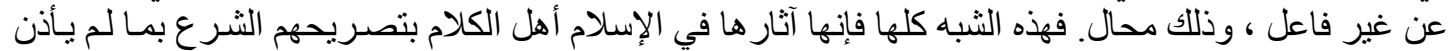

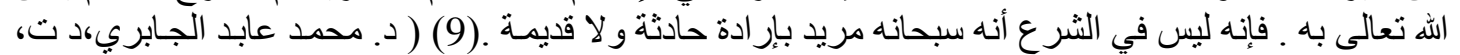




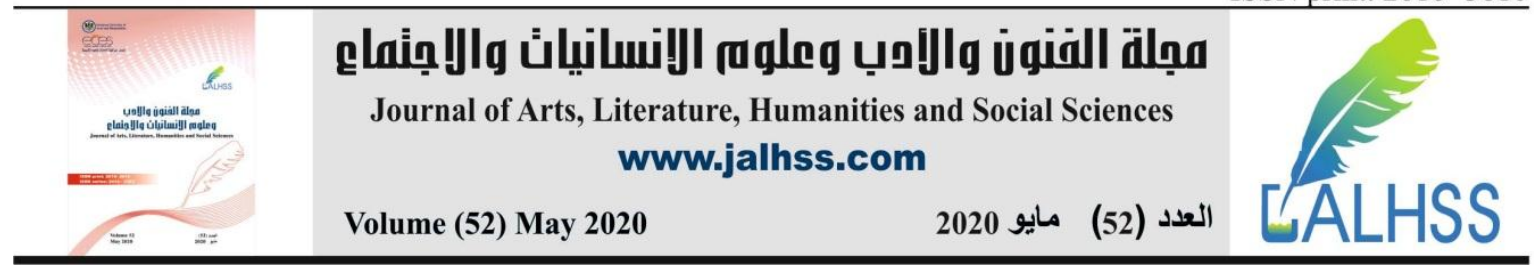

$$
\text { مشكلة قذام العالم }
$$

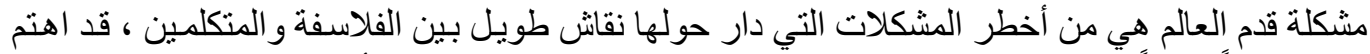

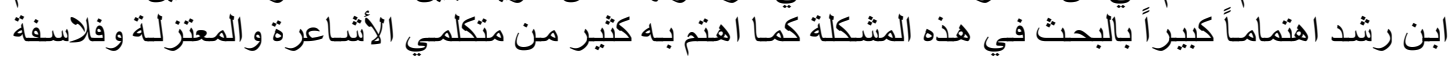
الغرب.

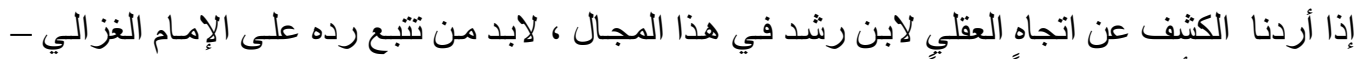

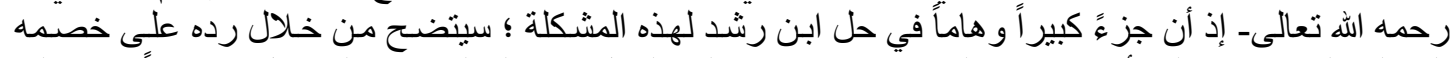

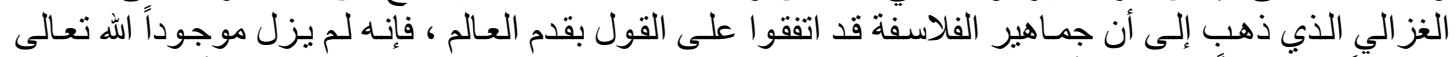

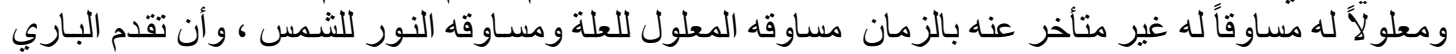

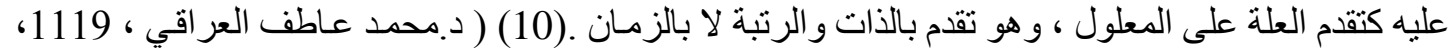

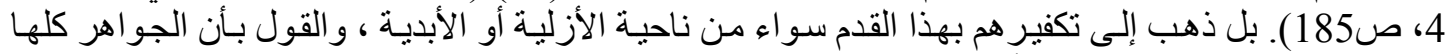

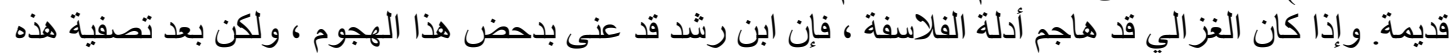

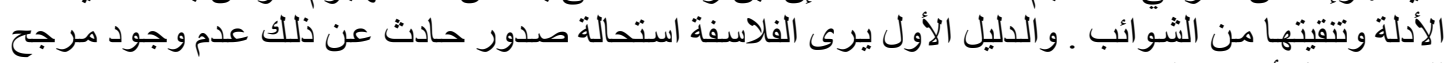

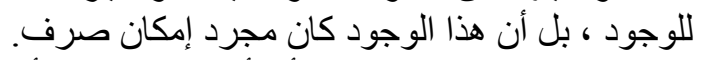

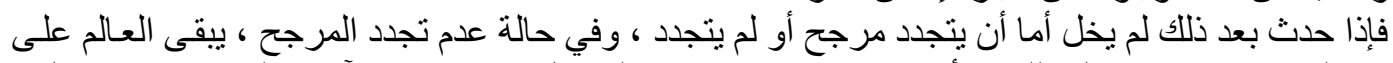

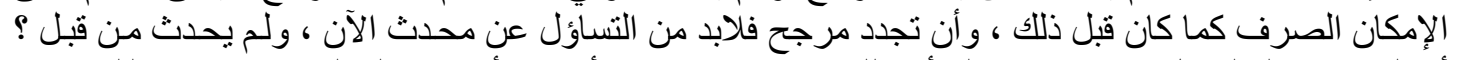

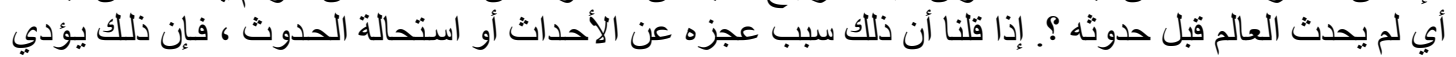
انقلاب القديم من العجز إلى القدرة العالم من الاستحالة إلى الإنى الإمكان.

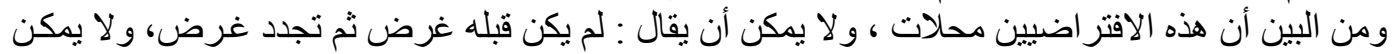

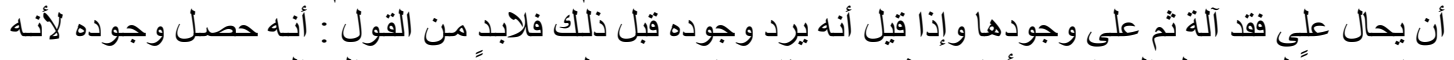

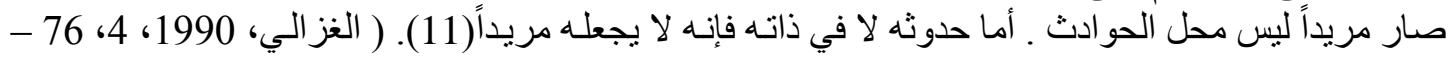

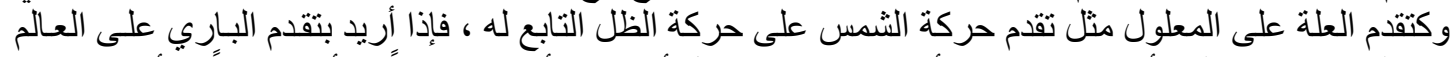

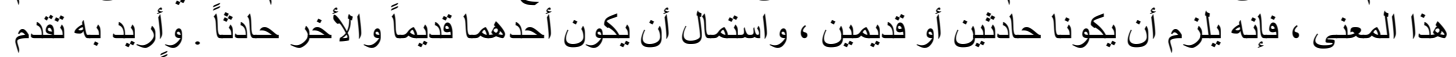

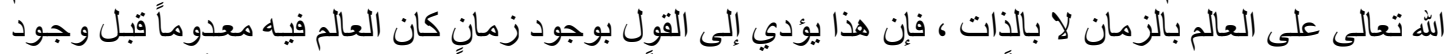

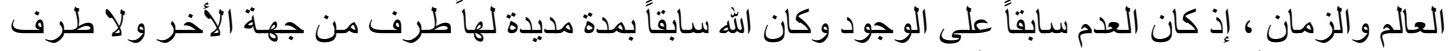

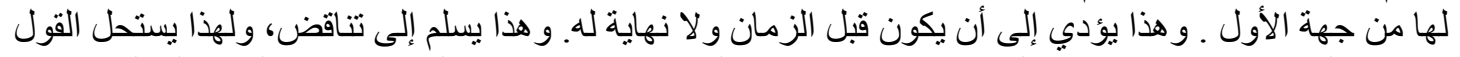

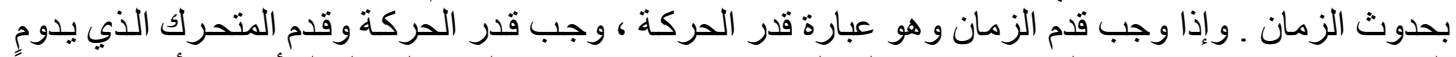

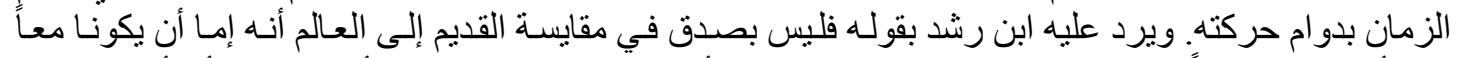

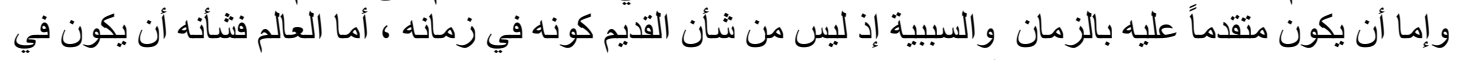

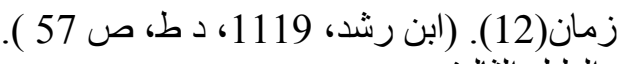

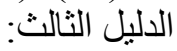

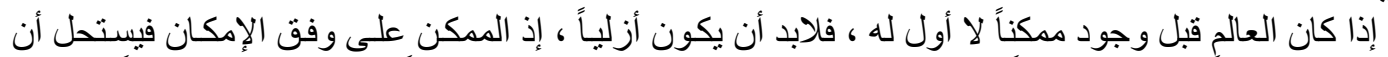

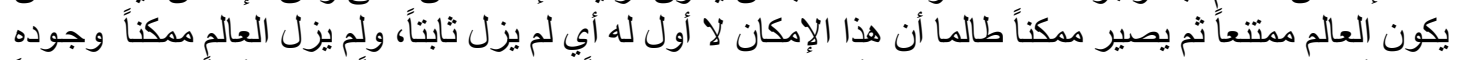

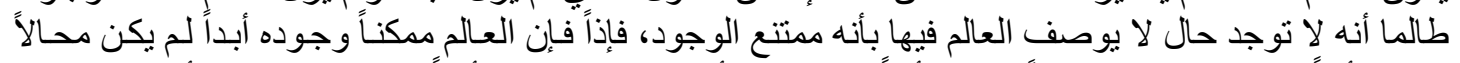

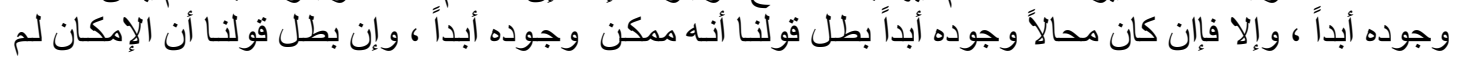




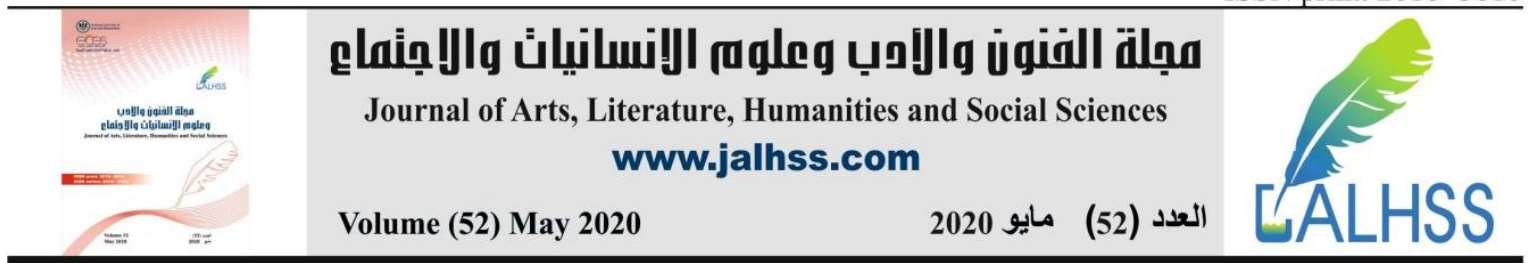

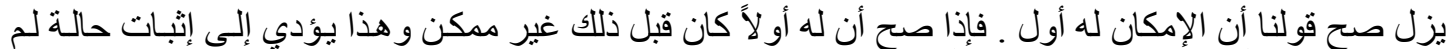

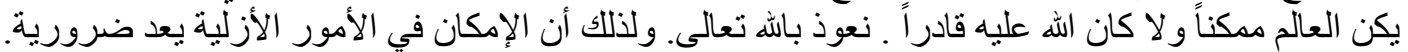

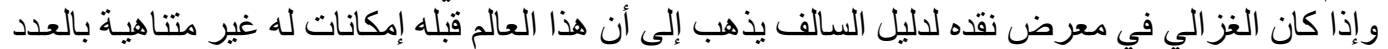

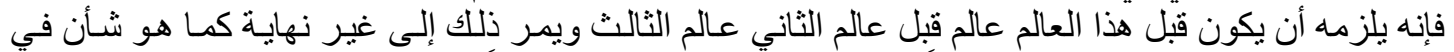

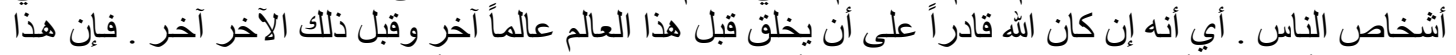

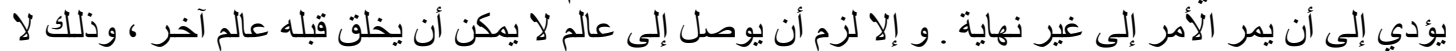

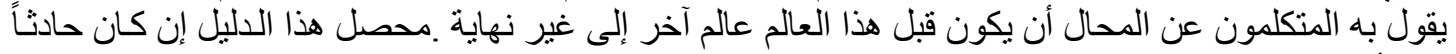

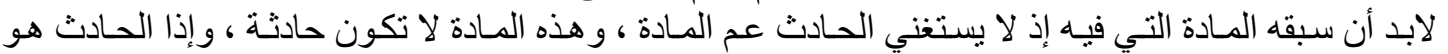

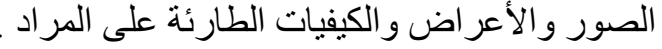

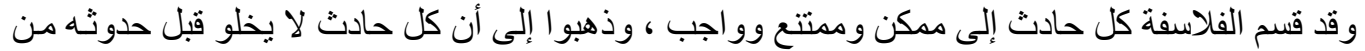

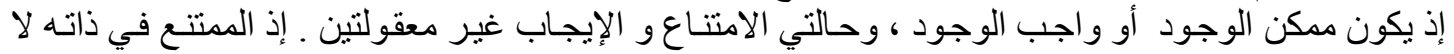

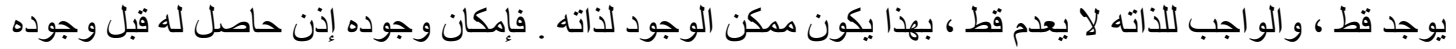

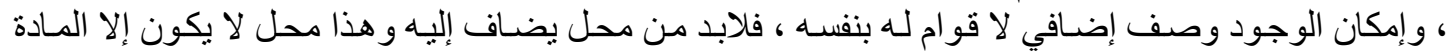

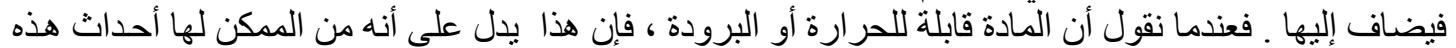
الكيفيات.

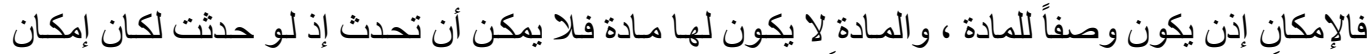

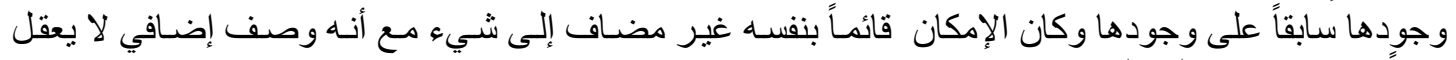

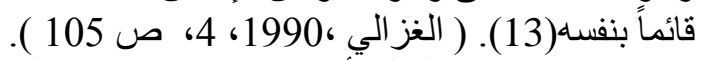

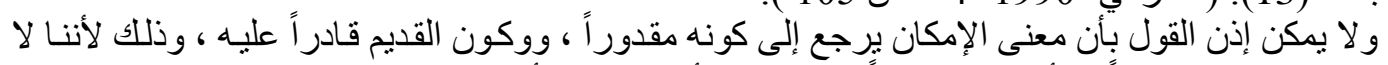

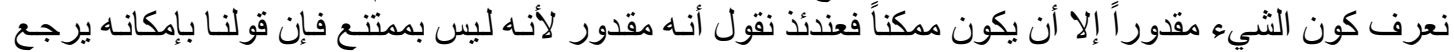

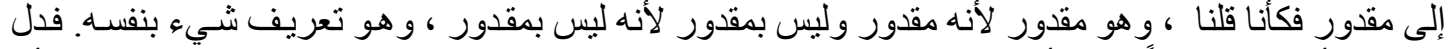

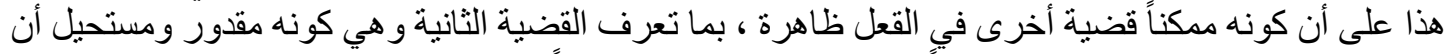

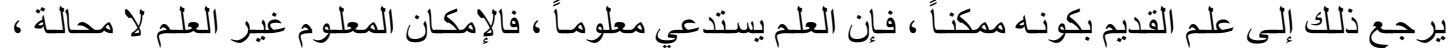

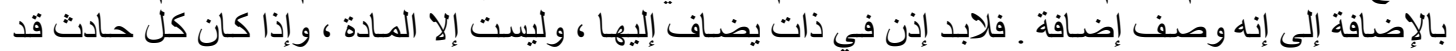

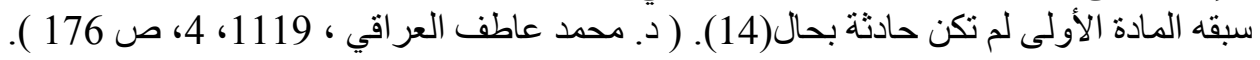

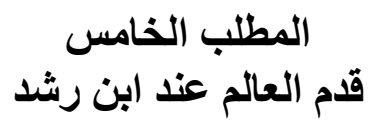

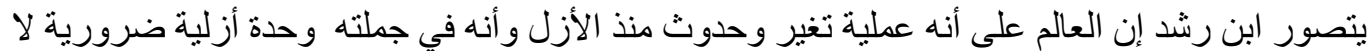

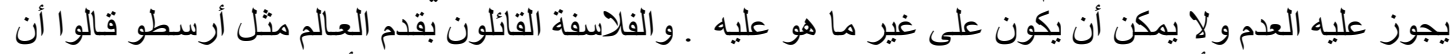

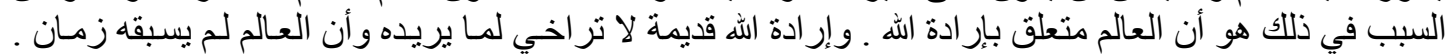

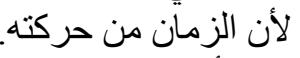

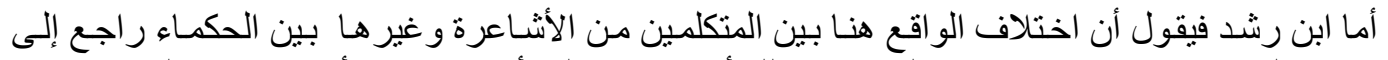

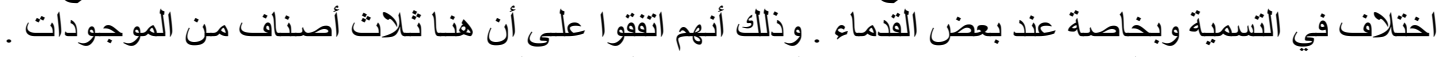

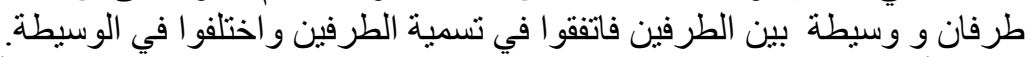

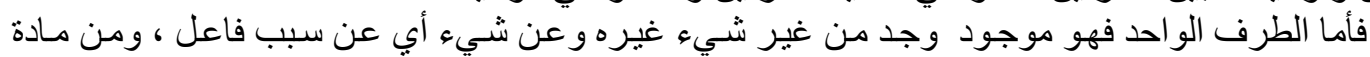

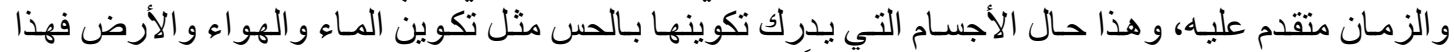

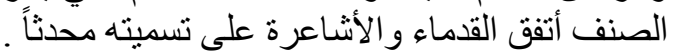

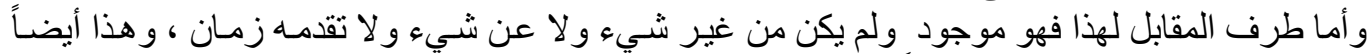

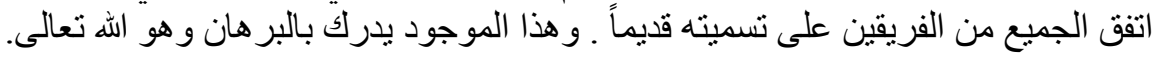




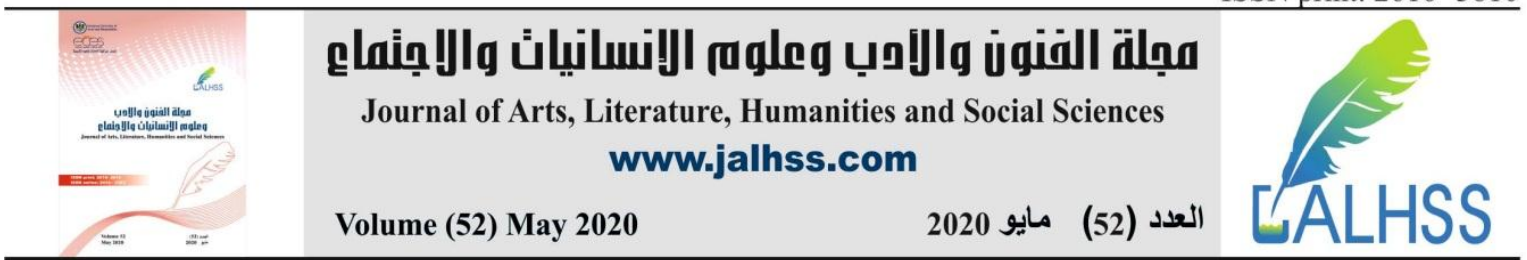

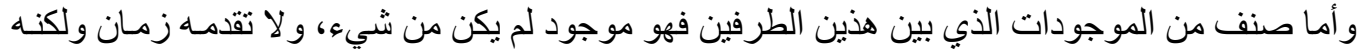

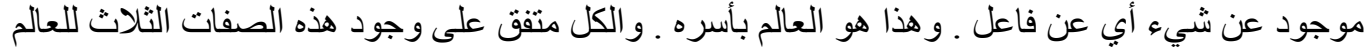

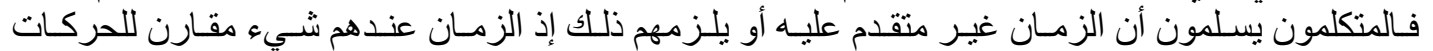

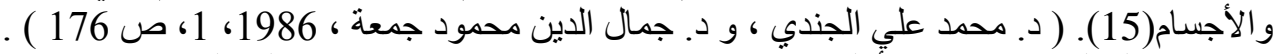

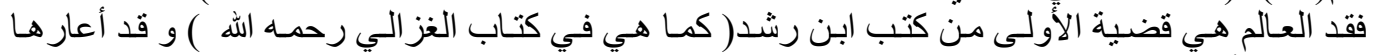

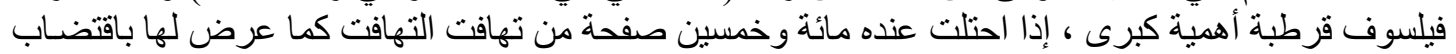

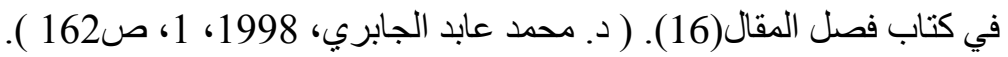

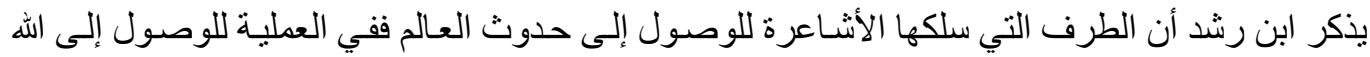

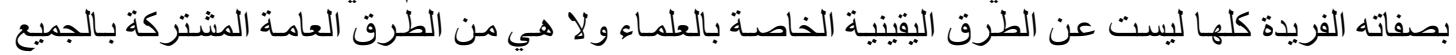

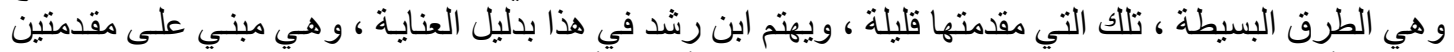

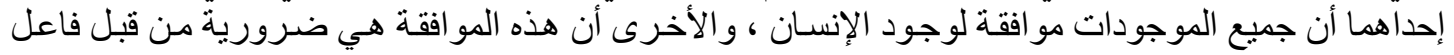

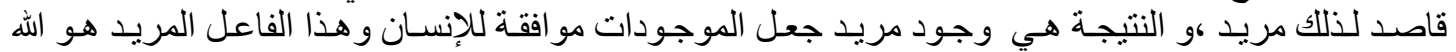

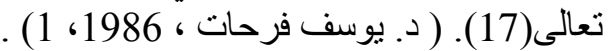

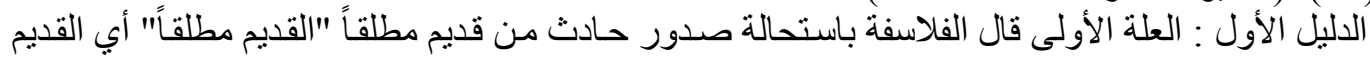

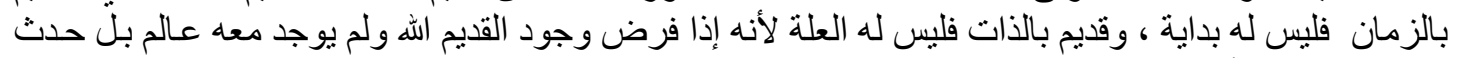

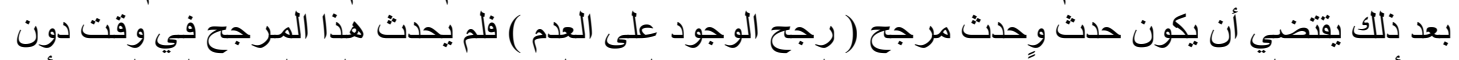

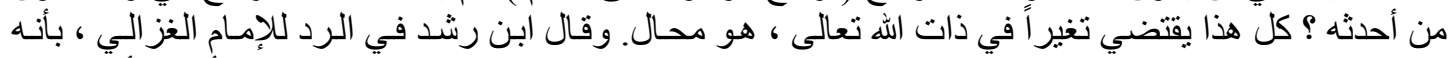

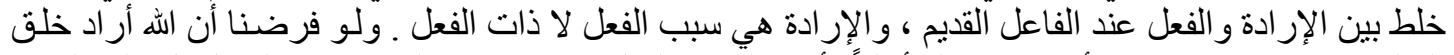

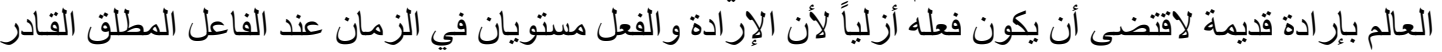

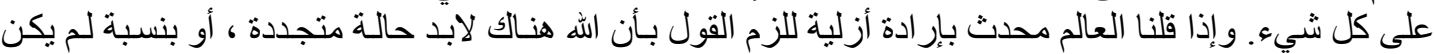

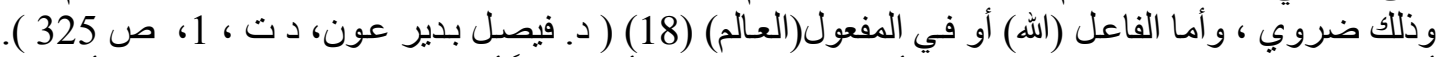

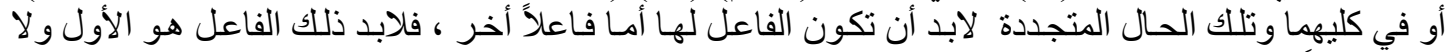

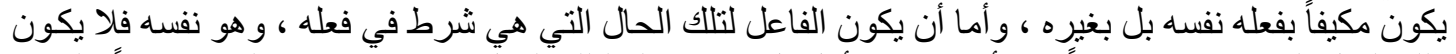

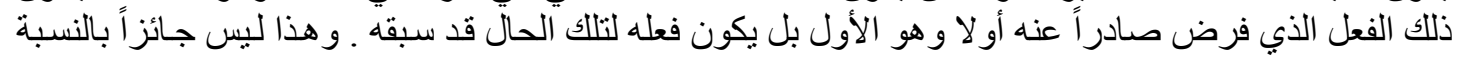

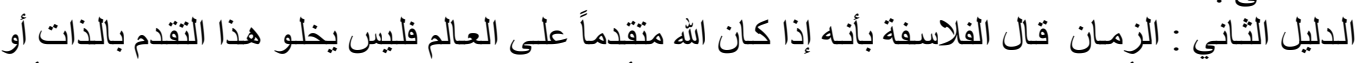

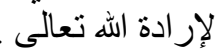

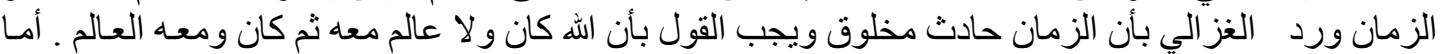

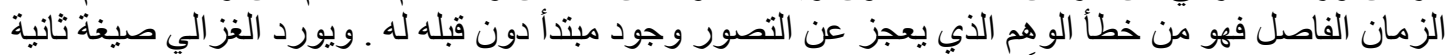

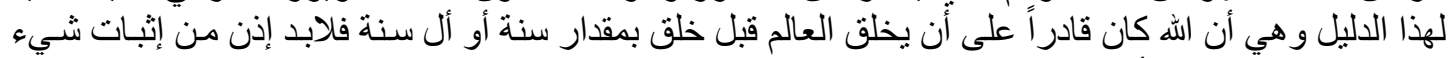

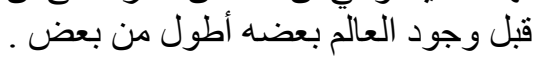

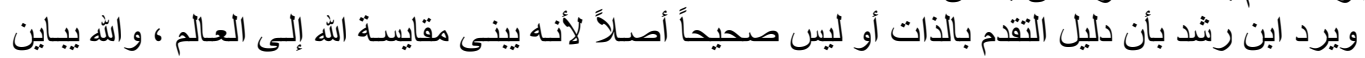

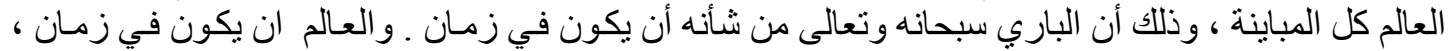

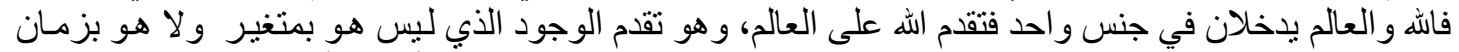

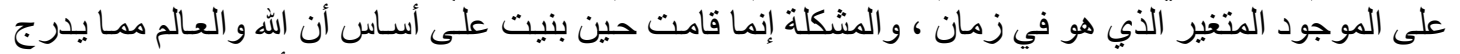

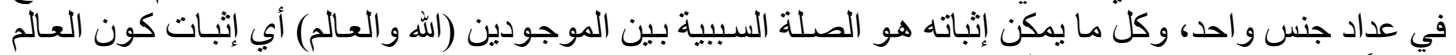

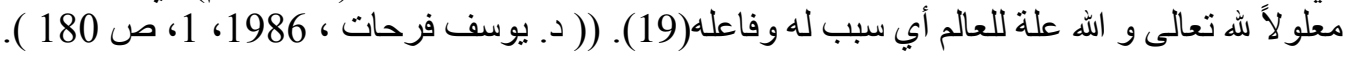

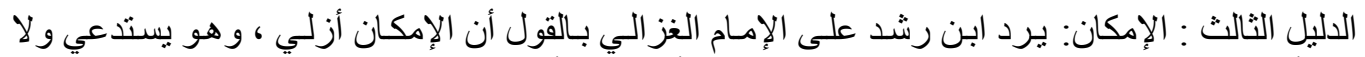

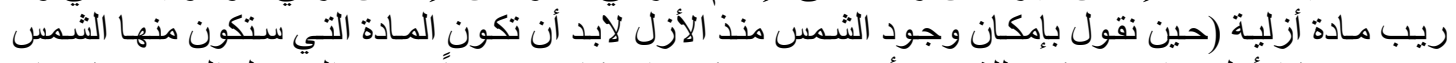

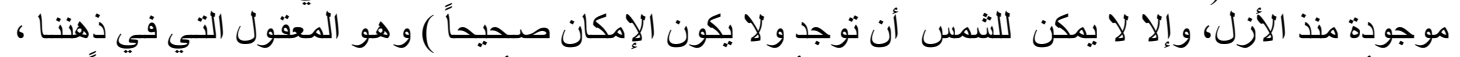

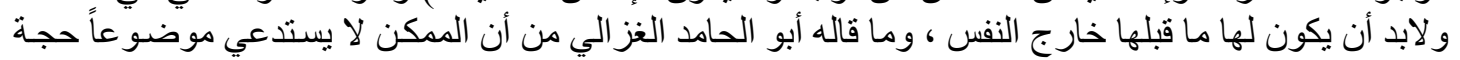

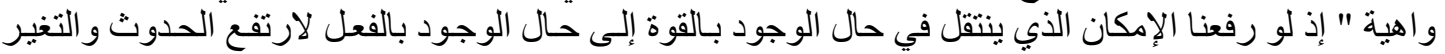




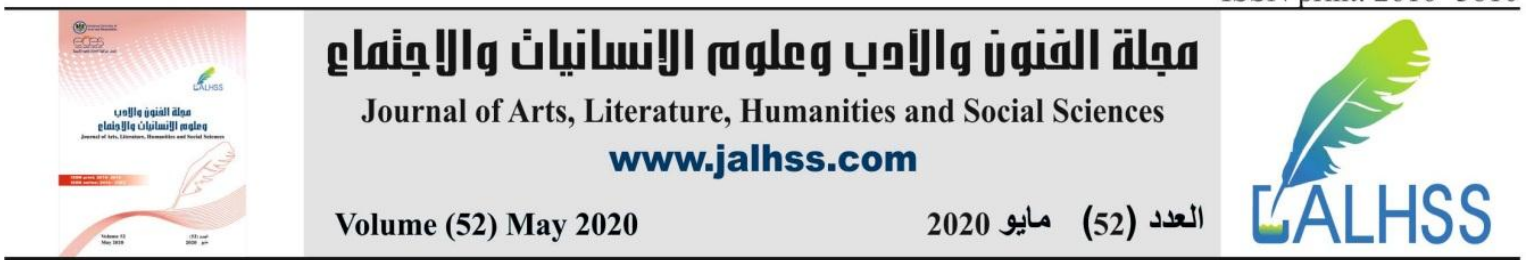

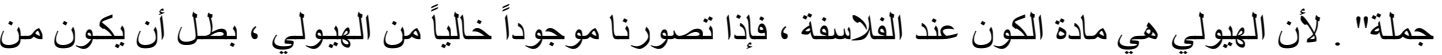

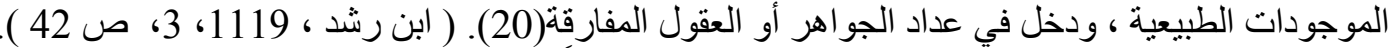

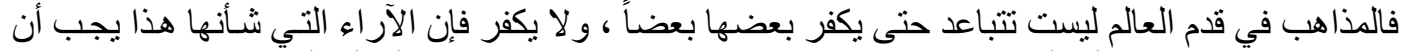

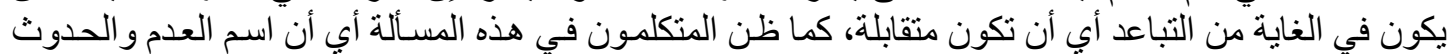
في العالم بأسره هو من المنقابلة وقد تبين من قولنا أن الأمر ليس كذلك.

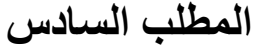 \\ أدلة ابن رشد لقدم العالم}

إن فلسفة المادية قد أعطت الأولية لمسألة قدم العالم وأزليته ، وجعلها المحل الأول للتمييز مـا بين الفكر

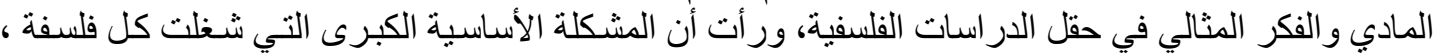

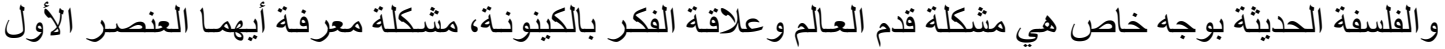

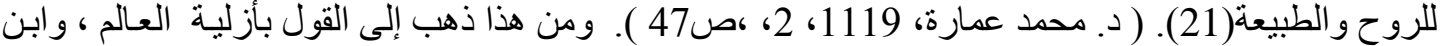

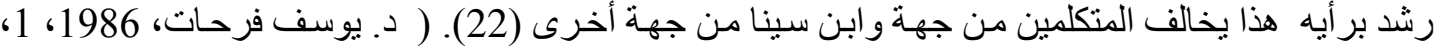

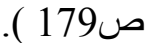

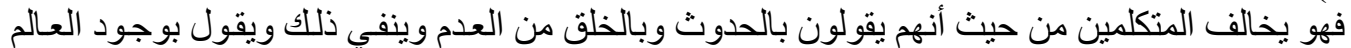

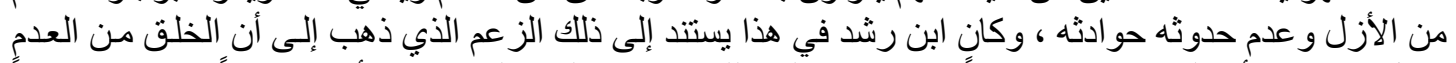

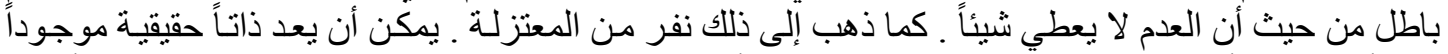

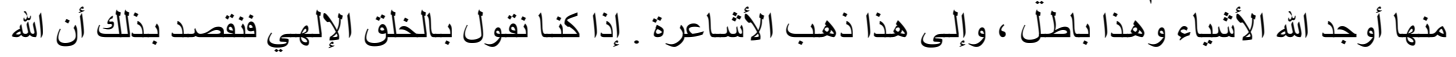

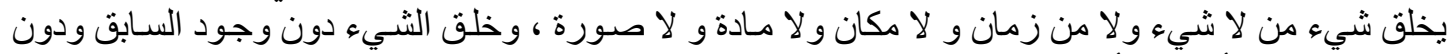

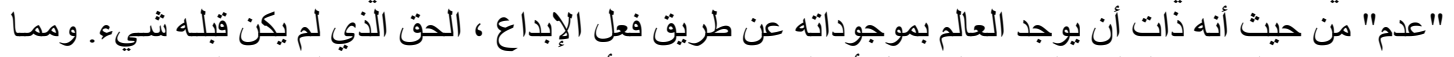

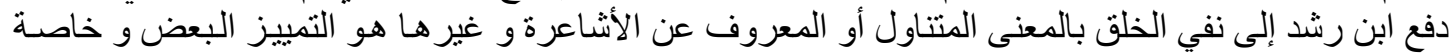

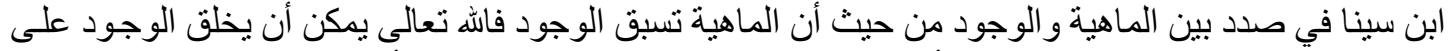

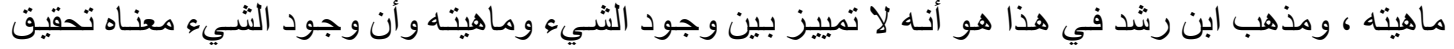

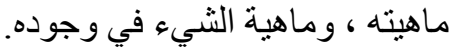

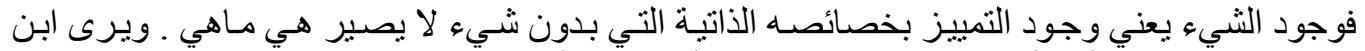

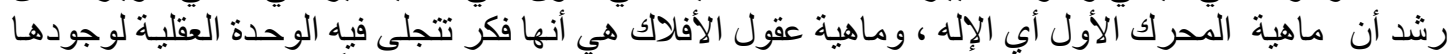

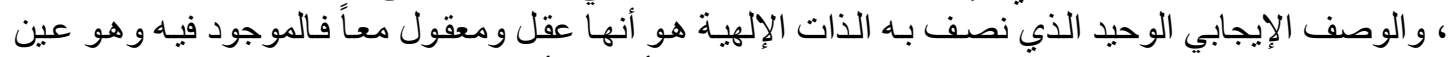

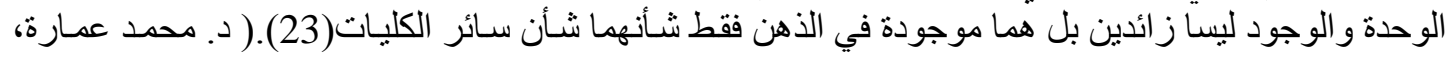

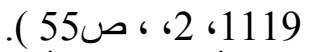

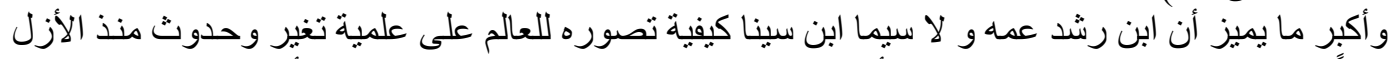

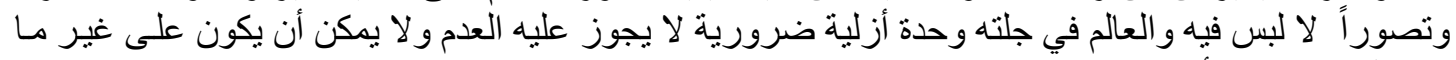

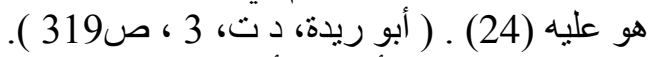

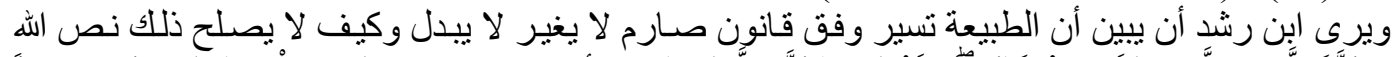

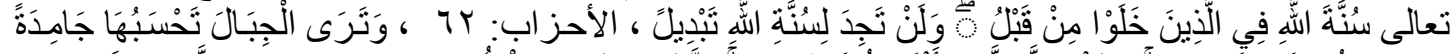

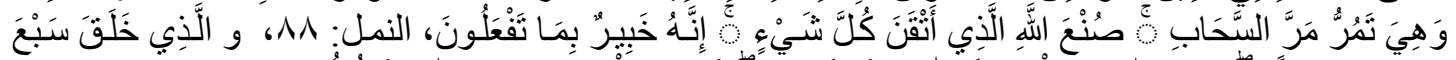

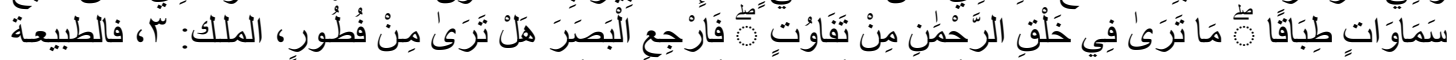

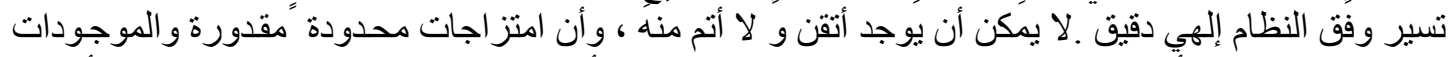

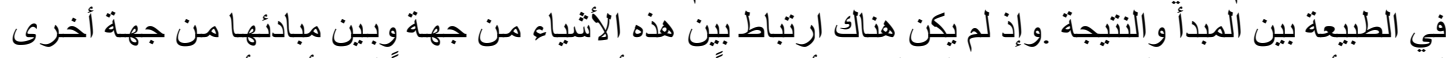

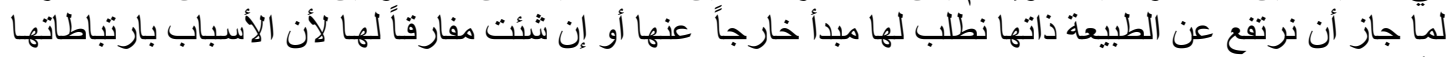

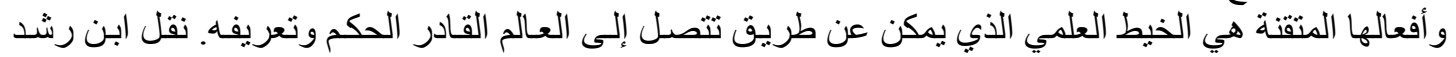




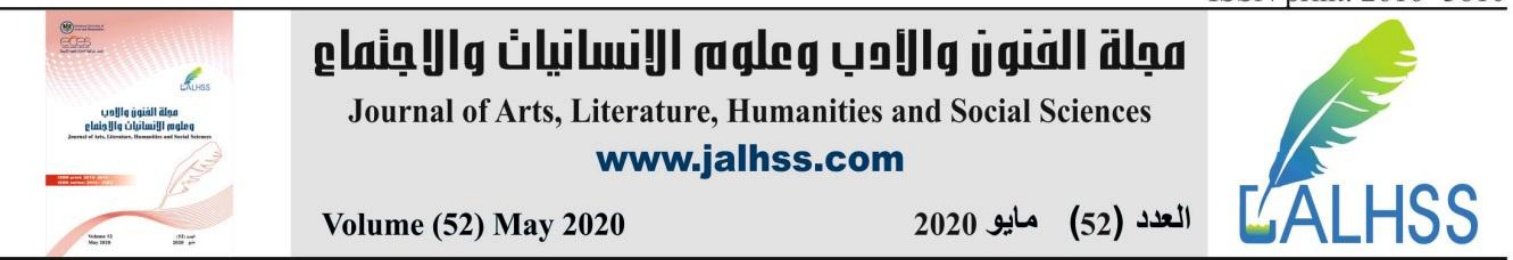

الأفكار فعل الأشياء بذانها وعدم انعكاس الثيء عن طبعه ، ونقل هذه الفكرة من المجال الطبيعي إلى المجال

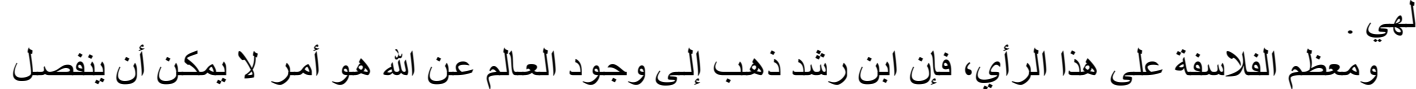

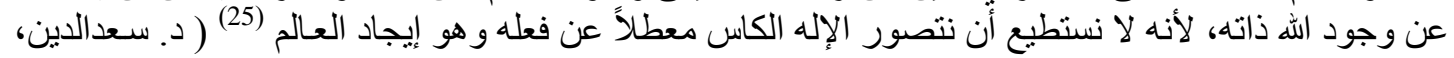

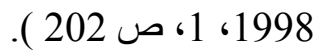

\section{نقد ابن رشد منكري قابم العالم السابع}

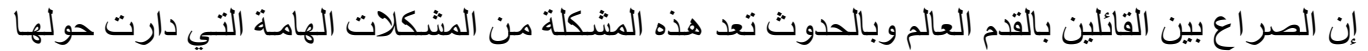

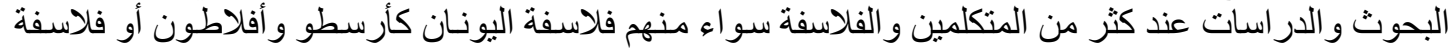

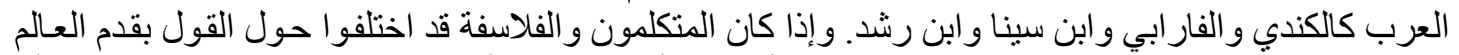

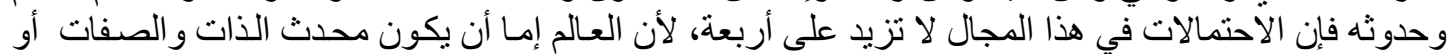

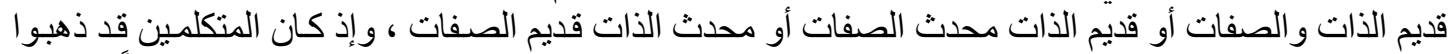

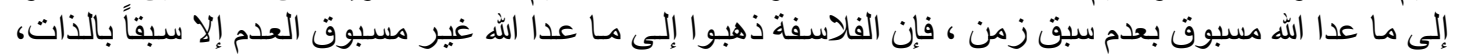

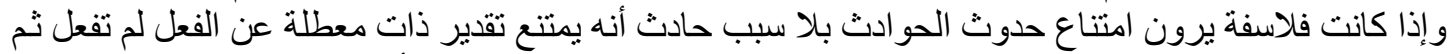

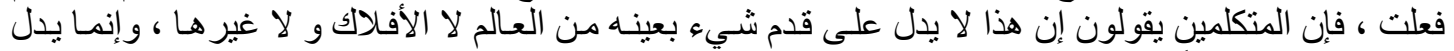

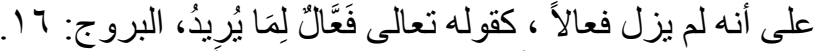

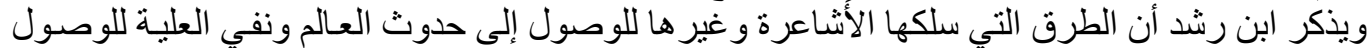

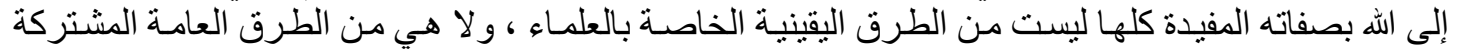

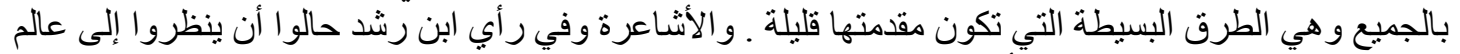

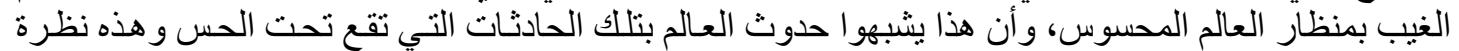

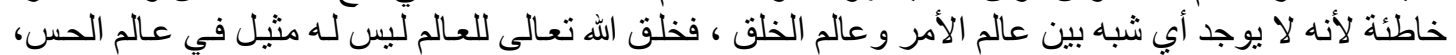

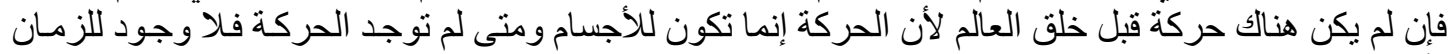

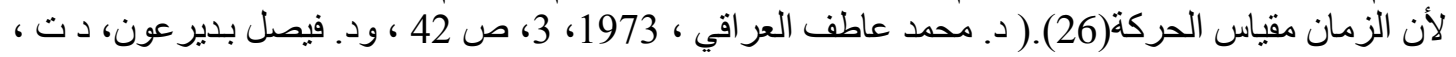

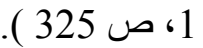

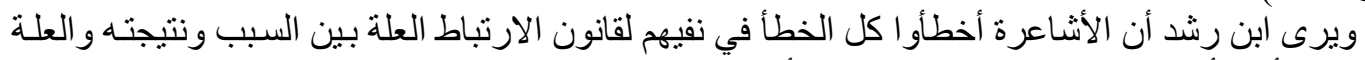

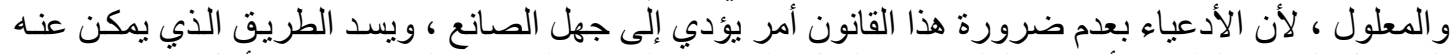

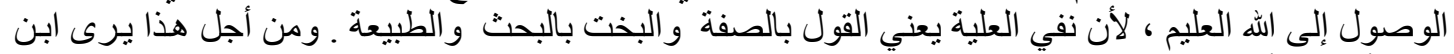

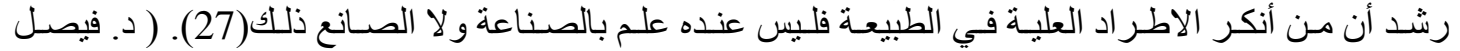

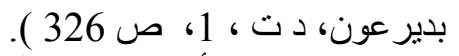

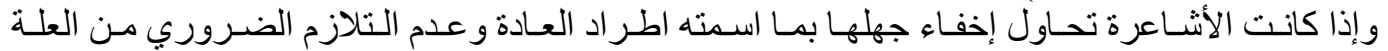

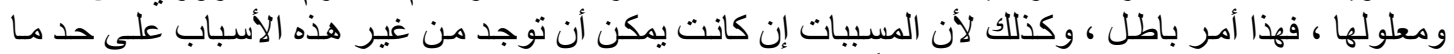

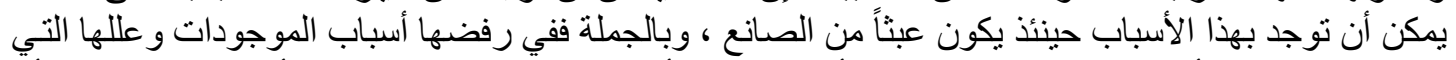

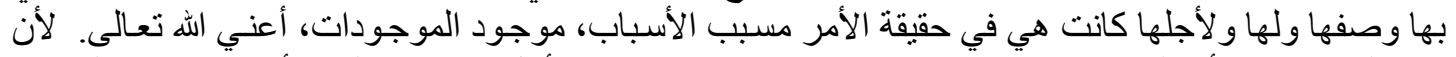

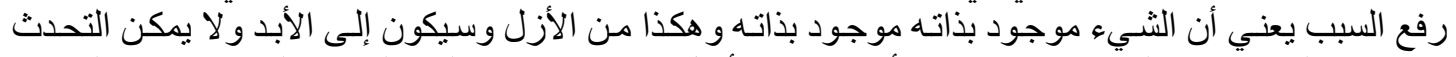

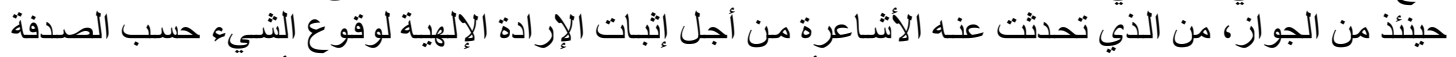

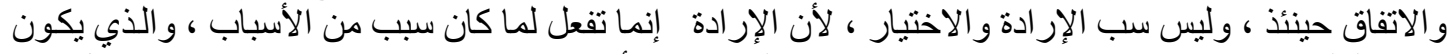

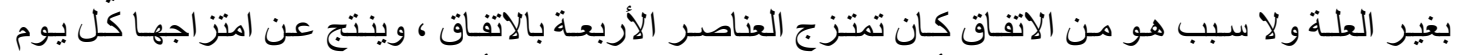

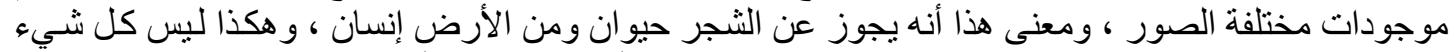

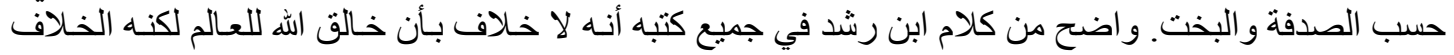




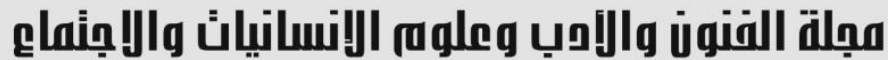

Journal of Arts, Literature, Humanities and Social Sciences www.jalhss.com

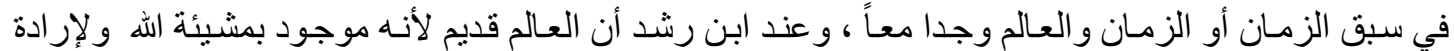

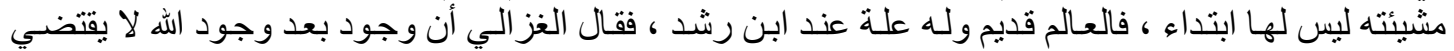

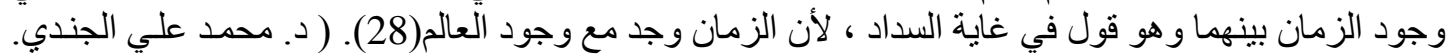

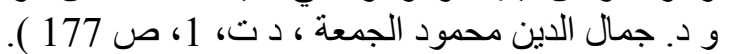

الخاتمة

بعد أن وصلنا إلى نهاية المطاف في هذا المبحث نختم الكلام عليه بما بلي :

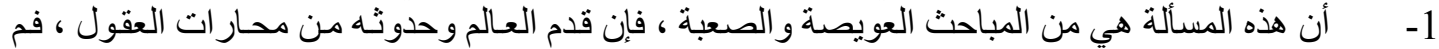

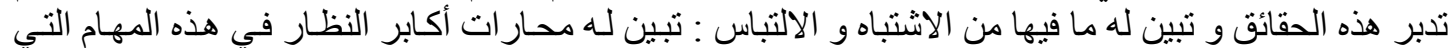

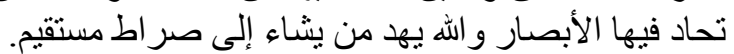

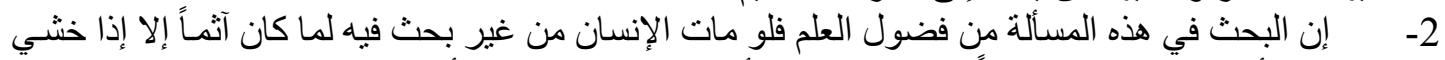

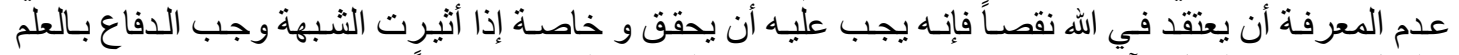

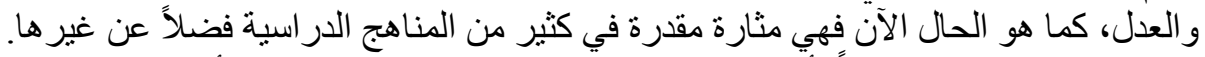

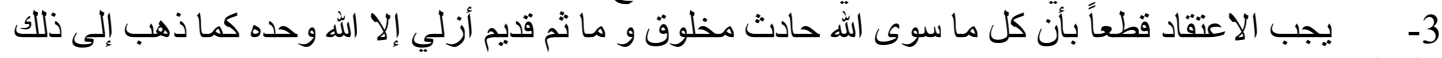

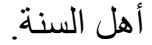

\section{الهوامش}

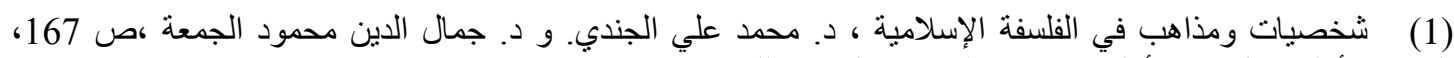

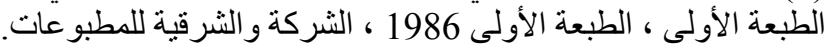

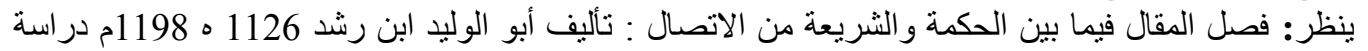

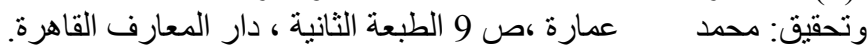

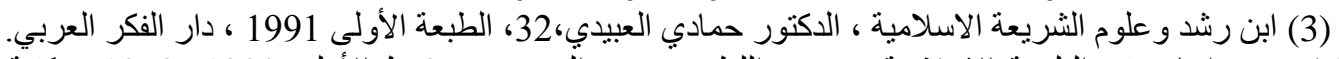

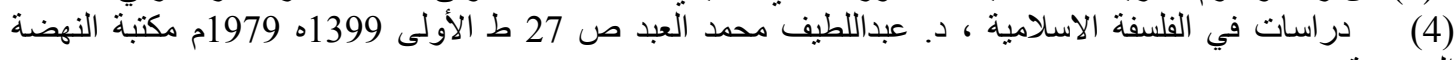

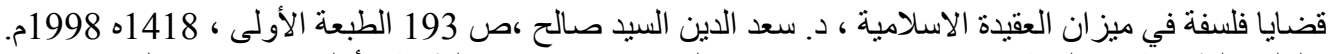

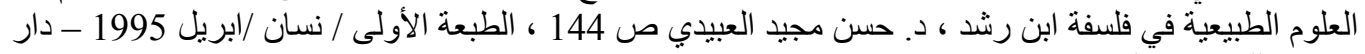

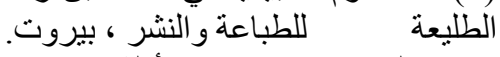
(7) الكثف عن مناهج الأدلة في عقائد الملة ، للاكتور محمد عابد الجابري، ص 171 الطبعة الأولى -بيروت -آذار

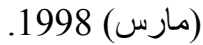

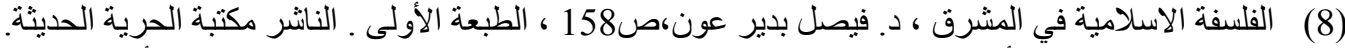

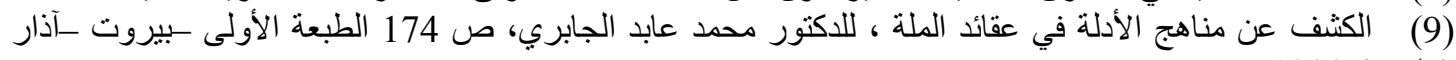
1998 (مارس (9) (10) النزعة العملية في فلسفة ابن رشد ، للاكتور محمد عاطف العراقي ،ص185، الطبعة الر ابعة دار المعارف 1119 كورنيش النيل ـالقاهرة

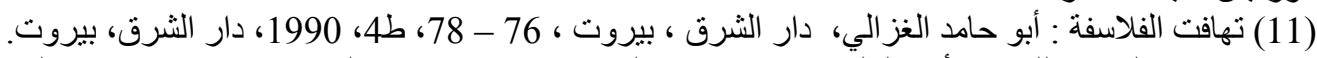

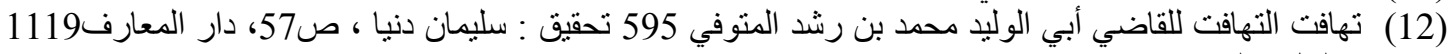

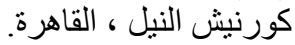

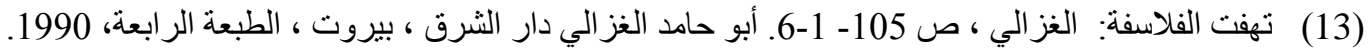

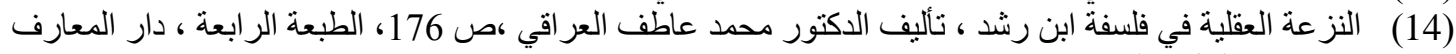
(15) ، 1119 كورنيش النيل ، القاهرة.

(15) شخصيات ومذاهب في الفلسفة الإسلامية ، د. محمد علي الجندي ، و د. جمال الدين محمود جمعة الفلسفة الإسلامية 


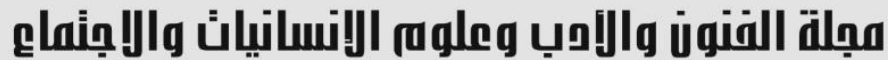

Journal of Arts, Literature, Humanities and Social Sciences www.jalhss.com

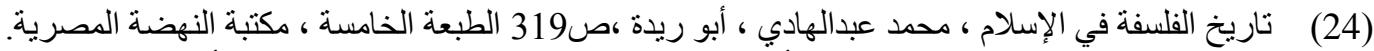

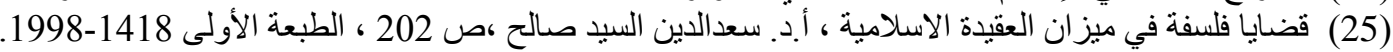

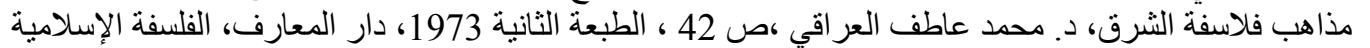

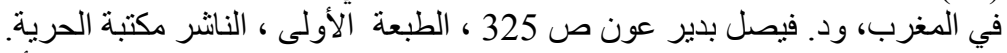

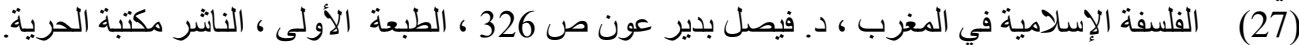

(28) شخيات ومذاهب في الفلسفة الإسلامية ، د. محمد علي الجندي. و د. دمال الدين محمود الجمعة ، 177، الطبعة

1- الجندي أ ، د. محمد علي و الجمعة جمال الدين محمود: شخصيات ومذاهب في الفلسفة الإسلامية ، الطبعة

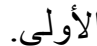

2- د. عبداللطيف محمد العبد: 1997، دراسات في الفلسفة الإسلاعية ، الطبعة الأولى، مكتبة النهضة الإنية المصرية.

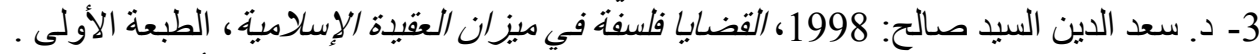

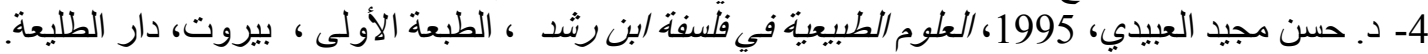

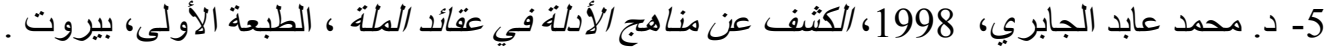

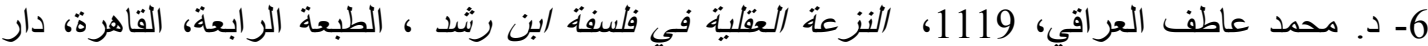

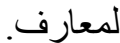
7- الغزالي: أبو حامد الغز الي، 1990، تهافت الفلاسفة ، الطبعة الرابعة، بيروت، دار الثرق.

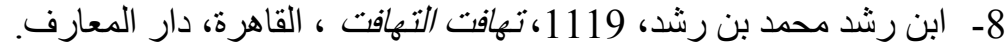

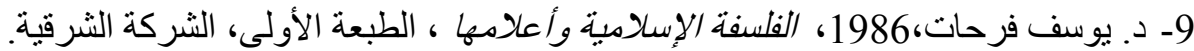

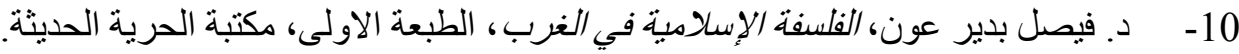

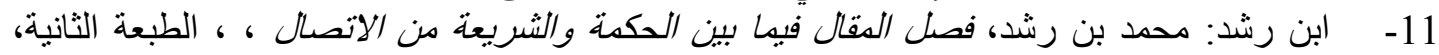
القاهرة، دار المعارف.

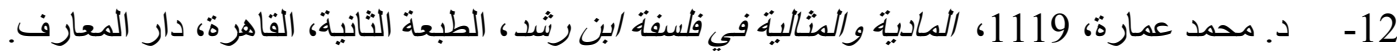

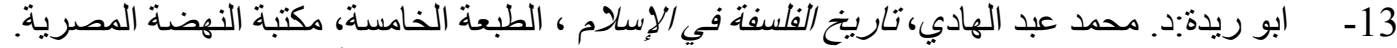

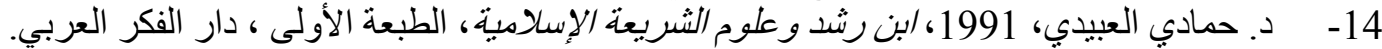
15- د. محمد عاطف العر اقي، 1973، مذادب لهب فلاسفة الثرق، الطبعة الثانية، دار المعارف. 


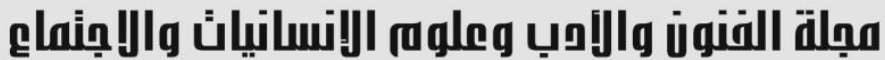

Journal of Arts, Literature, Humanities and Social Sciences

www.jalhss.com

\section{References}

1- AL JONDY A, D. Muhammad Ali and Friday Jamaluddin Mahmoud: personalities and doctrines in Islamic philosophy, first edition.

2- Dr. Abd al-Latif Muhammad al-Abd: 1997, studies in Islamic philosophy, first edition, Egyptian Renaissance Library.

3- Dr. Saad al-Din al-Sayyid Salih: 1998, issues are philosophy in the balance of Islamic belief, first edition.

4- Dr. Hassan Majeed Al-Ubaidi, 1995, Natural Sciences in Ibn Rushd's Philosophy, First Edition, Beirut, Dar Al-Tale'ah.

5- Dr. Muhammad Abid al-Jabri, 1998, Unveiling the Curricula of Evidence in the Creeds of the Millah, First Edition, Beirut.

6- Dr. Muhammad Atif al-Iraqi, 1119, Mental Trends in Ibn Rushd's Philosophy, Fourth Edition, Cairo, Dar Al-Maarif.

7- Al-Ghazali: Abu Hamid Al-Ghazali, 1990, The Rush of Philosophers, Fourth Edition, Beirut, Dar Al-Sharq.

8- Ibn Rushd Muhammad bin Rushd, 1119, rush of rush, Cairo, Dar al-Maarif.

9- Dr. Youssef Farhat, 1986, Islamic Philosophy and its Sciences, First Edition, The Eastern Company.

10- Dr. Faisal Badir Aoun, Islamic Philosophy in the West, First Edition, Modern Freedom Library.

11- Ibn Rushd: Muhammad bin Rushd, article separating wisdom and Sharia from communication, second edition, Cairo, Dar Al-Maarif.

12- Dr. Mohamed Amara, 1119, Materialism and Idealism in Ibn Rushd's Philosophy, Second Edition, Cairo, Dar Al-Maarif.

13- Abu Reeda: Dr. Muhammad Abd al-Hadi, History of Philosophy in Islam, Fifth Edition, Egyptian Renaissance Library.

14- Dr. Hammadi Al-Ubaidi, 1991, Ibn Rushd and the Sciences of Islamic Sharia, first edition, Dar Al-Fikr Al-Arabi.

16- Dr. Muhammad Atef al-Iraqi, 1973, doctrines of Eastern philosophers, second edition, Dar Al-Maarif. 